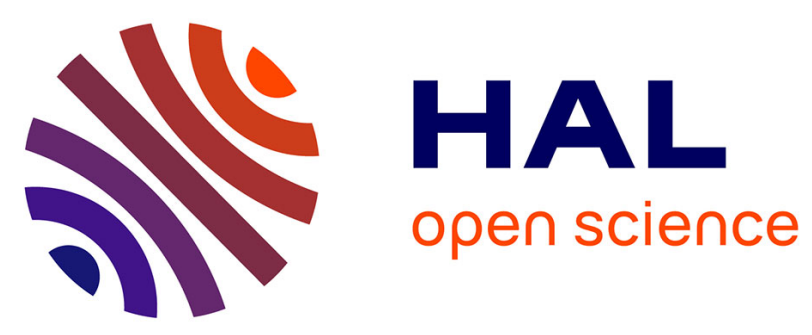

\title{
Posteucritic magmatism on Vesta: Evidence from the petrology and thermal history of diogenites
}

\author{
A. Yamaguchi, Jean-Alix J-A Barrat, Ito Motoo, Marcel Bohn
}

\section{To cite this version:}

A. Yamaguchi, Jean-Alix J-A Barrat, Ito Motoo, Marcel Bohn. Posteucritic magmatism on Vesta: Evidence from the petrology and thermal history of diogenites. Journal of Geophysical Research, 2011, 116, pp.E08009. 10.1029/2010JE003753 . insu-00617210

\section{HAL Id: insu-00617210 \\ https://hal-insu.archives-ouvertes.fr/insu-00617210}

Submitted on 26 Feb 2012

HAL is a multi-disciplinary open access archive for the deposit and dissemination of scientific research documents, whether they are published or not. The documents may come from teaching and research institutions in France or abroad, or from public or private research centers.
L'archive ouverte pluridisciplinaire HAL, est destinée au dépôt et à la diffusion de documents scientifiques de niveau recherche, publiés ou non, émanant des établissements d'enseignement et de recherche français ou étrangers, des laboratoires publics ou privés. 


\title{
Posteucritic magmatism on Vesta: Evidence from the petrology and thermal history of diogenites
}

\begin{abstract}
Akira Yamaguchi, ${ }^{1,2}$ Jean-Alix Barrat, ${ }^{3,4}$ Motoo Ito, ${ }^{5,6,7}$ and Marcel Bohn ${ }^{4}$
Received 7 October 2010; revised 5 May 2011; accepted 1 June 2011; published 26 August 2011.

[1] We report on the petrology and the thermal histories of 13 diogenites in order to constrain the formation processes of the Vestan crust. We classify diogenites into unequilibrated and equilibrated diogenites in a scheme similar to that for basaltic eucrites. Pyroxenes in unequilibrated diogenites are chemically zoned, indicating that they crystallized rapidly from melts and escaped from global crustal metamorphism. The presence of unequilibrated diogenites casts doubt on the fact that all the diogenites formed at depth in the parent body, as commonly thought. Some diogenites probably crystallized in shallow intrusions or were extruded on the surface. These facts strengthen the geochemical evidence that diogenites and eucrites are not directly cogenetic and suggest that at least some diogenites have intruded the early formed eucritic crust. Thus, diogenites are certainly not the products of the crystallization of the magma ocean that triggered the differentiation of Vesta but are more likely cumulates associated with a later stage of magmatism. Furthermore, the intrusion of diogenites could have significantly thickened the early formed crust, making it difficult to excavate deep-seated olivine mantle by moderate impact events.
\end{abstract}

Citation: Yamaguchi, A., J.-A. Barrat, M. Ito, and M. Bohn (2011), Posteucritic magmatism on Vesta: Evidence from the petrology and thermal history of diogenites, J. Geophys. Res., 116, E08009, doi:10.1029/2010JE003753.

\section{Introduction}

[2] In September 2007, the Dawn spacecraft was launched to the asteroid belt and will begin studying the asteroid 4 Vesta in July 2011 [Russell et al., 2007]. Vesta is not just one more small body that will be studied by a spacecraft. This asteroid is thought to be the parent body of the largest group of achondrites, the so-called HED (howardites, eucrites and diogenites) meteorites [McCord et al., 1970; Binzel and Xu, 1993]. Infrared spectroscopy indicates that Vesta displays a basaltic surface with some ultramafic spots, but unfortunately the Earth-based observations have insufficient resolution to accurately describe the various lithologic units or to precisely define their relationships [Binzel et al., 1997; Gaffey, 1997; Shestopalov et al., 2010]. Indeed, the planned remote sensing studies that will be undertaken by the Dawn spacecraft should allow the identification of mineralogically distinct areas on Vesta, and may well provide a geological framework for the various types of HED meteorites.

\footnotetext{
${ }^{1}$ National Institute of Polar Research, Tokyo, Japan.

${ }^{2}$ Department of Polar Science, School of Multidisciplinary Science, Graduate University for Advanced Sciences, Tokyo, Japan.

${ }^{3}$ Université Européenne de Bretagne, Brest, France.

${ }^{4}$ Domaines Océaniques, UMR 6538, Université de Brest, CNRS, IUEM, Plouzané, France.

${ }^{5}$ Robert M Walker Laboratory for Space Science, NASA Johnson Space Center, Houston, Texas, USA.

${ }^{6}$ Lunar and Planetary Institute, Houston, Texas, USA.

${ }^{7}$ Now at Kochi Institute for Core Sample Research, JAMSTEC, Nankoku, Japan.

Copyright 2011 by the American Geophysical Union. 0148-0227/11/2010JE003753
}

[3] At present, the differentiation history of Vesta has been mostly inferred from petrological, geochemical and geochronological studies of HED meteorites, but no consensus model has yet emerged. Depletions of siderophile elements in HED meteorites and homogeneous oxygen isotopic compositions suggest that igneous portions of HED meteorites are products of extensive melting and crystallization in a magma ocean [Hewins and Newsom, 1988; Righter and Drake, 1997; Greenwood et al., 2005]. Eucrites are considered to be residual basaltic liquids that extruded onto the surface whereas diogenites are orthopyroxene-rich ultramafic cumulates whose parental magmas are not well constrained. Earlier studies suggest that diogenites are cumulate rocks directly crystallized from a magma ocean [e.g., Mason 1962; Righter and Drake, 1997; Takeda, 1997; Warren, 1997]. However, the bulk chemical data and major and trace elements compositions of diogenitic pyroxenes indicate much more complex petrogenetic histories. Several workers have pointed out that eucrites and diogenites cannot be comagmatic on the basis of these bulk data. Mittlefehldt [1994] and Fowler et al. [1995] proposed that diogenites crystallized from multiple magmas. The parental melts of diogenites could have formed from the remelting of the magma ocean cumulates [Barrat, 2004; Barrat et al., 2008]. Moreover, rare earth element variations (and particularly the deep negative Eu anomalies) of many diogenites can be explained in terms of interaction of the parental magmas and early formed eucritic crust [Barrat et al., 2010].

[4] To better understand the geologic processes that operated on the Vestan crust, detailed investigations on the geochemistry and thermal histories of diogenites are required. Here, we report on the textures and mineralogy of 13 dio- 
Table 1. Characteristics of Samples Used in This Study ${ }^{\mathrm{a}}$

\begin{tabular}{|c|c|c|c|c|c|c|}
\hline & \multirow[b]{2}{*}{ Pyroxene $\mathrm{Mg}^{\prime}$} & \multirow[b]{2}{*}{ Type } & & \multirow[b]{2}{*}{ Eq/Uneq } & \multicolumn{2}{|c|}{ Pyroxene } \\
\hline & & & & & Fe-Mg Zoning & Ca Zoning \\
\hline A-87147 & 75.1 & Dio & Breccia & $\mathrm{Eq}$ & no & no \\
\hline A-880785 & $73.4-74.8$ & Dio & Breccia & $\mathrm{Eq}$ & no & no \\
\hline A-880936 & $71.2-75.0$ & Dio & Breccia & $\mathrm{Eq}$ & no & no \\
\hline A-881239 & $74.1-75.2$ & Dio & Breccia & $\mathrm{Eq}$ & no & no \\
\hline A-881377 & $74.8-75.4$ & Ol D & Breccia & Intermediate & no & yes \\
\hline A-881526 & 75.4 & Dio & Breccia & $\mathrm{Eq}$ & no & no \\
\hline A-881548 & 78.0 & Ol D & Breccia & $\mathrm{Eq}$ & no & no \\
\hline A- 881838 & $70.3-70.5$ & Dio & Breccia & $\mathrm{Eq}$ & no & no \\
\hline A-881839 & $69.8-70.5$ & Dio & Breccia & $\mathrm{Eq}$ & no & no \\
\hline A-881944 & $70.8-71.2$ & Dio & Breccia & $\mathrm{Eq}$ & no & no \\
\hline Dho 700 & $69.1-69.8$ & Dio & Unbrecciated & Uneq & yes & yes \\
\hline NWA 1877 & $75.6-75.9$ & Ol D & Breccia & $\mathrm{Eq}$ & no & no \\
\hline Y-74097 & $74.7-74.9$ & Dio & Recrystallized & Uneq & yes & yes \\
\hline
\end{tabular}

${ }^{\mathrm{a}} \mathrm{Mg}^{\prime}=$ molar $\mathrm{Mg} /(\mathrm{Mg}+\mathrm{Fe}) \times 100$. Dio, diogenite, $\mathrm{Ol} \mathrm{D}$, olivine-bearing diogenite. Eq, equilibrated diogenite; Uneq, unequilibrated diogenite.

genites and demonstrate that some of them have certainly not formed in a deep plutonic setting, as commonly thought. These data have profound implications for the history of the parent body, and imply that diogenites, at least in part, could be among the most recent magmatic rocks formed on Vesta. This paper is a companion work to the paper by Barrat et al. [2010].

\section{Samples and Analytical Procedures}

[5] We studied Dhofar (Dho) 700, northwest Africa (NWA) 1877, two hot desert diogenites, and 11 other diogenites from Antarctica. The polished thin sections (PTSs) of Asuka and Yamato diogenites (Asuka (A)-87147,71-1, A-880785,51-1, A-880936,51-1, A-881239,51-1, A-881377,63-1, A-881526,51-1 and, 59-1, A-881548,31-1 and, 51-2, A881838,32-1, A-881839,51-1, A-881944,51-2, Yamato (Y)74097,64-1) were supplied from the National Institute of Polar Research, Tokyo (NIPR). Two PTSs were made from different portions of the main mass of A-881548 (110.2 g) to ensure the distribution of olivine was understood. These samples were also allocated for companion geochemical studies [Barrat et al., 2008, 2010]. Characteristics of the samples studied are presented in Table 1.

[6] PTSs of these diogenites were examined using an optical microscope equipped with both transmitted and reflected light, a scanning electron microscope (SEM) (JSM5900LV) equipped with an energy dispersive spectrometer (EDS) (Oxford Link-ISIS), and an electron microprobe analyzers (EPMA) (JXA8200) at NIPR, and SX-100 at IUEM in Brest). Mineral compositions are presented in Tables 2-4. Mineral modes were determined by X-ray mapping. Silica polymorphs were identified using a laser micro-Raman spectrometer (JASCO NRS-1000) at NIPR.

\section{Results}

\subsection{Textures}

\subsubsection{Dhofar 700}

[7] Dho 700 is one of the rare unbrecciated diogenites and displays a granular texture composed of pyroxene ( $\sim 99 \mathrm{vol} \%)$ with minor phases such as plagioclase, chromite, olivine, silica minerals (cristobalite and tridymite), Fe-FeS, and weathering products (Figure 1a). Pyroxene grains ( $3 \mathrm{~mm}$ in the largest dimension) generally are elongated with irregular outlines. Elongated, wedge-shaped crystals of plagioclase and silica minerals $(<100 \mu \mathrm{m}$ thick) occur interstitially between the pyroxene grains (Figure $2 \mathrm{a}$ ). Fe-FeS occur as tiny inclusions ( $<$ a few to several $\mu \mathrm{m}$ ) in the orthopyroxene grain and as isolated inclusions (20-30 $\mu \mathrm{m}$ in size), and are in many cases replaced by weathering products. Chromite occurs as chains of tiny grains $(<3-4 \mu \mathrm{m})$ along healed fractures, as small irregular grains $(<3-4 \mu \mathrm{m})$, and exceptionally as larger grains $(\sim 200 \times 80 \mu \mathrm{m})$ surrounded by thin plagioclase rims. The weathering products (carbonate?) occur along cracks and fractures pervasively. One thin section contains pore spaces.

[8] The rims of granular pyroxenes have thin $(\sim 1-2 \mu \mathrm{m}$ thick) discontinuous lamellae or wormy blebs of augite along (100) (Figure 1b). The rims in many cases have sharp streaks under crossed polarized light. The orthopyroxene cores are dusty due to the presence of fine $(<\mathrm{a}$ few $\mu \mathrm{m})$ inclusions of Fe-FeS. The orthopyroxene grains contain sparse maficrich inclusions $(\sim 100-200 \mu \mathrm{m}$ in size) which are rounded, subrounded, and in some cases irregular.

\subsubsection{Ferroan Diogenites A-881838 and A-881839}

[9] A-881838 and A-881839 are brecciated ferroan diogenites $\left(\mathrm{Mg}^{\prime}(=\right.$ molar $\left.\mathrm{Mg} /(\mathrm{Mg}+\mathrm{Fe}) \times 100)=69.8-70.5\right)$. They are probably paired because their textures and mineral compositions are similar (Figure 1c). These diogenites are composed of pyroxenes ( $96-97$ vol \%) with minor amounts of plagioclase, silica minerals, chromite, and FeS. The A-881839 section contains a greater abundance of plagioclase (3 vol \%) in contrast to that of A-881838 ( 1 vol \%). Clasts and fragments are often $>4 \mathrm{~mm}$. A-881839 PTS contains areas $(\sim 1.5 \mathrm{~mm}$ in size $)$ of brecciated domains composed of plagioclase grains $(<0.2 \mathrm{~mm})$ and elongated plagioclase $(\sim 0.1 \times 0.2 \mathrm{~mm})$. A-881838 contains a large isolated grain of chromite $(1.4 \times 0.6 \mathrm{~mm})$ attached to thin films of plagioclase.

[10] Some grains of orthopyroxene contain fine (less than several microns) blebs and fine (less than a few microns) augite lamellae concentrated along the grain boundaries (Figure 1d). Occasionally, rare grains of augite (several tens of microns) can be found. The pyroxene textures are similar to that of inverted pigeonite in Y-75032 type diogenite [e.g., Taked and Mori, 1985; Saiki et al., 2001].

\subsubsection{Olivine-Bearing Diogenites A-881548 and NWA 1877}

[11] A-881548 and NWA 1877 are slightly brecciated diogenites mainly composed of pyroxene and olivine (i.e., 


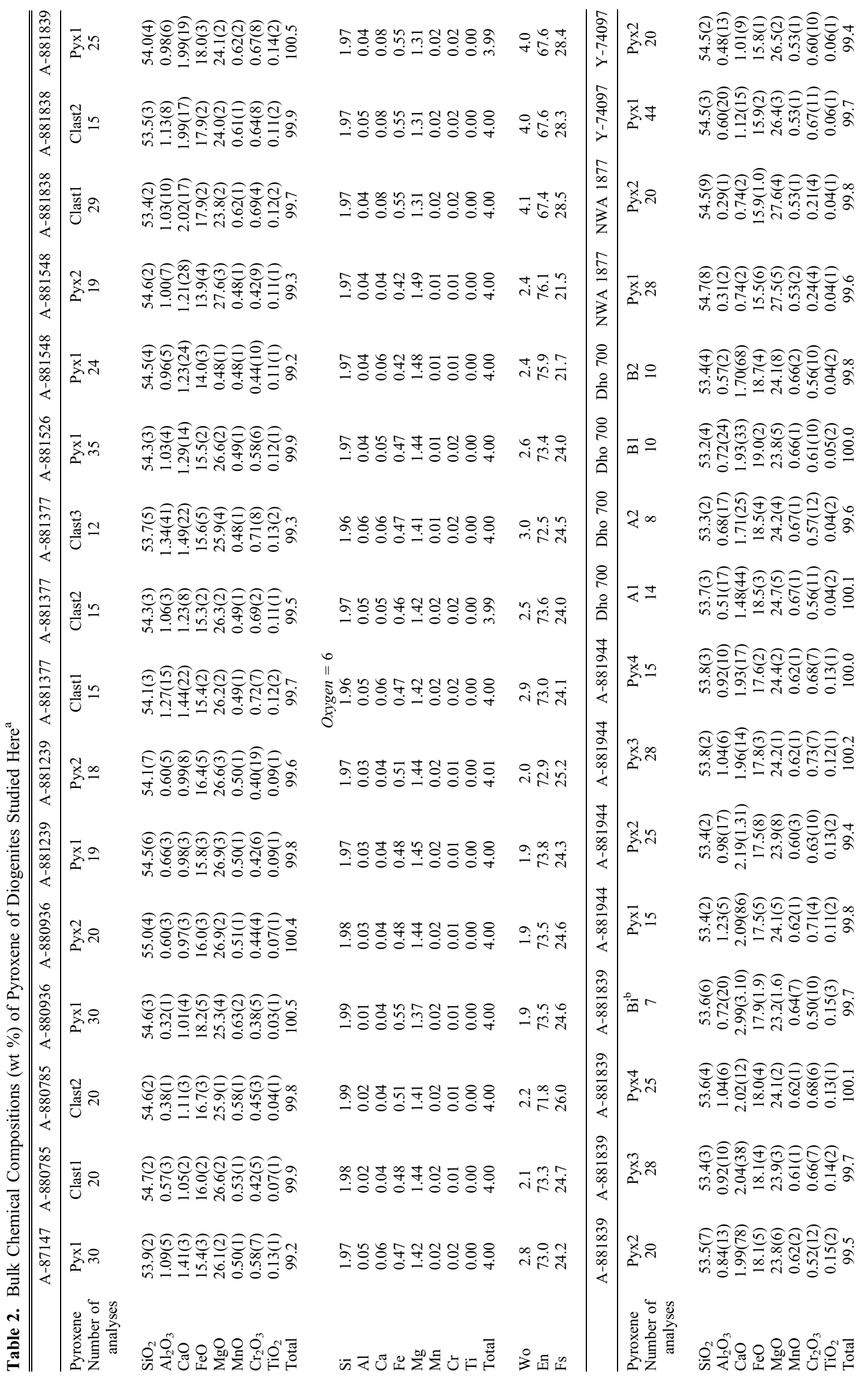


harzburgitic diogenites [Beck and McSween., 2010]) (Figure 1e). Minor minerals include chromite and Fe-FeS. No plagioclase or silica minerals are observed in the PTSs. These diogenites are composed of areas of crystalline portion with some brecciated areas. Pyroxene and olivine grains in A-881548 are larger than $\sim 1 \mathrm{~cm}$, whereas those of NWA 1877 are smaller $(\sim 1-3 \mathrm{~mm}$ in size $)$. NWA 1877 is severely weathered because FeS and FeNi metals are mostly replaced by weathering products. Although these two diogenites contain large amounts of olivine, the $\mathrm{Mg}^{\prime}$ values are different $\left(\mathrm{Mg}^{\prime}=78\right.$ for $\mathrm{A}-881548$ and $\mathrm{Mg}^{\prime}=76$ for NWA 1877). We examined two PTSs of A-881548 obtained from different locations from the main mass (110.2 g). One thin section of A-881548 contain $46 \mathrm{vol} \%$ of olivine. The other section contains $\sim 80$ vol $\%$ of olivine. However, a chip (0.1312 g) used for chemical study showed no signature of olivine [Barrat et al., 2008]. The samples, including the chip used for the analysis are too small to be representative of the whole rock because of the large size of the crystals (about $1 \mathrm{~cm}$ ). Coarse olivine grains in A-881548 are probably heterogeneously distributed in the main mass.

[12] Grains of pyroxenes and olivine in these olivinebearing diogenites have generally sharp or slightly curved grain boundaries except in brecciated portions. In A-881548 and NWA 1877, chromite occurs as isolated grains some of which occur as thin (20-30 $\mu \mathrm{m}$ thick) irregular worms, forming an oblong ring in A-881548. In NWA 1877, a large chromite grain $(2.1 \times 1.2 \mathrm{~mm})$ in contact with FeNi metal $(0.8 \times 0.5 \mathrm{~mm})$ surrounded by weathering products has been observed. Troilite occurs as irregular grains of various sizes (up to $1.1 \times 1.6 \mathrm{~mm}$ ). In olivine and along grain boundaries between large olivine and pyroxene grains, there are small FeS grains $(\sim 10-100 \mu \mathrm{m}$ in size $)$ that are associated with orthopyroxene forming irregular or elongated assemblages (0.2-0.4 $\mathrm{mm}$ thick and $3 \mathrm{~mm}$ in the maximum dimension). Augite typically occurs in pyroxene and the smaller grains are associated with the FeS-orthopyroxene assemblages ( $0.8 \mathrm{~mm}$ in the longest dimension in A-881548).

\subsubsection{A-881377}

[13] A-881377 is a breccia, and contains a significant amount of olivine ( $\sim 5 \mathrm{vol} \%$ ) (Figure 1f). The minor minerals include plagioclase $(\sim 1 \mathrm{vol} \%), \mathrm{Fe}-\mathrm{FeS}(0.4 \mathrm{vol} \%)$, and silica minerals. The sizes of the clasts vary from $\sim 1$ to $5 \mathrm{~mm}$ in the PTS. The common mineralogical features in pyroxenes in clasts and matrix fragments indicate that this rock is mostly composed of olivine-bearing (or harzburgitic) diogenite.

[14] Olivine occurs in harzburgitic clasts and as fragments in the clastic matrix $(<1 \mathrm{~mm})$. In harzburgitic clasts, boundaries between coarse olivine and orthopyroxene are smooth and curved, and in some cases have thin bands of fine wormy and irregular chromite grains $(\sim 2-10 \mu \mathrm{m})$ partially surrounded by fine orthopyroxene grains $(\sim 10-30 \mu \mathrm{m})$. Plagioclase $(\sim 100 \mu \mathrm{m}$ maximum) occurs interstitially along grain boundaries. Occasionally grains of plagioclase up to $0.3 \mathrm{~mm}$ are observed. FeS occurs as isolated grains from $\sim$ a few to several hundred $\mu \mathrm{m}$, in many cases associated with $\mathrm{Fe}$ metal. We found a few grains of silica mineral in the clastic matrix.

\subsection{5. $Y-74097$}

[15] Y-74097 is one of the Yamato-A type diogenites (e.g., Y-74013, Y-74136, and Y-74037), which have been previously described by Takeda et al. [1981] and Mittlefehldt and 
Table 3. Representative Analyses of Pyroxene, Olivine, and Chromite in Diogenties Studied Here

\begin{tabular}{|c|c|c|c|c|c|c|c|}
\hline & \multicolumn{2}{|c|}{ Pyroxene $^{\mathrm{a}}$} & & \multicolumn{4}{|c|}{ Olivine $^{\mathrm{b}}$} \\
\hline & Dho $700^{c}$ & Dho $700^{d}$ & & A881377 & A881548 & Dho $700^{c}$ & NWA1877 \\
\hline $\mathrm{SiO}_{2}$ & 55.0 & 54.5 & & 38.2 & 38.6 & 38.3 & 37.6 \\
\hline $\mathrm{Al}_{2} \mathrm{O}_{3}$ & 0.59 & 0.25 & & 0.04 & $<0.01$ & $<0.01$ & $<0.01$ \\
\hline $\mathrm{CaO}$ & 1.13 & 1.51 & & 0.04 & 0.01 & 0.08 & 0.03 \\
\hline $\mathrm{FeO}$ & 15.4 & 19.0 & & 25.8 & 21.8 & 25.8 & 25.0 \\
\hline $\mathrm{MgO}$ & 26.9 & 24.5 & & 36.3 & 40.0 & 36.6 & 37.0 \\
\hline $\mathrm{MnO}$ & 0.69 & 0.64 & & 0.52 & 0.47 & 0.75 & 0.51 \\
\hline $\mathrm{Cr}_{2} \mathrm{O}_{3}$ & 0.34 & 0.27 & & $<0.02$ & 0.02 & 0.04 & $<0.02$ \\
\hline $\mathrm{TiO}_{2}$ & 0.05 & $<0.02$ & & $<0.02$ & 0.02 & $<0.02$ & 0.01 \\
\hline $\mathrm{V}_{2} \mathrm{O}_{3}$ & 0.03 & $<0.02$ & & $<0.01$ & $<0.01$ & $<0.01$ & \\
\hline Total & 100.2 & 100.7 & & 100.8 & 100.9 & 101.5 & 100.1 \\
\hline $\mathrm{Si}$ & 1.98 & 1.99 & & 2.00 & 1.98 & 2.00 & 1.98 \\
\hline $\mathrm{Al}$ & 0.03 & 0.01 & & 0.00 & 0.00 & 0.00 & 0.00 \\
\hline $\mathrm{Ca}$ & 0.04 & 0.06 & & 0.00 & 0.00 & 0.00 & 0.00 \\
\hline $\mathrm{Fe}$ & 0.46 & 0.58 & & 1.13 & 0.94 & 1.12 & 1.10 \\
\hline $\mathrm{Mg}$ & 1.45 & 1.33 & & 2.83 & 3.07 & 2.84 & 2.91 \\
\hline $\mathrm{Mn}$ & 0.02 & 0.02 & & 0.02 & 0.02 & 0.03 & 0.02 \\
\hline $\mathrm{Cr}$ & 0.00 & 0.00 & & 0.00 & 0.00 & 0.00 & 0.00 \\
\hline $\mathrm{Ti}$ & 0.01 & 0.00 & & 0.00 & 0.00 & 0.00 & 0.00 \\
\hline V & 0.00 & 0.00 & & 0.00 & 0.00 & 0.00 & \\
\hline Total & 3.99 & 4.00 & & 6.00 & 6.01 & 6.00 & 6.02 \\
\hline $\mathrm{Wo}^{\mathrm{e}}$ & 2.2 & 3.0 & $\mathrm{Mg}^{\prime}$ & 71.5 & 76.6 & 71.7 & 72.5 \\
\hline $\mathrm{En}^{\mathrm{e}}$ & 74.0 & 67.5 & & & & & \\
\hline $\mathrm{Fs}^{\mathrm{e}}$ & 23.7 & 29.5 & & & & & \\
\hline
\end{tabular}

\begin{tabular}{|c|c|c|c|c|c|c|c|c|c|}
\hline & \multicolumn{9}{|c|}{ Chromite $^{\mathrm{b}}$} \\
\hline & A-87147 & A-880785 & A-880936 & A-881239 & A-881377 & A-881377 & A- 881548 & A- 881838 & A- 881838 \\
\hline $\mathrm{SiO}_{2}$ & $<0.02$ & 0.05 & 0.04 & 0.03 & 0.19 & 0.16 & $<0.02$ & 0.17 & $<0.02$ \\
\hline $\mathrm{Al}_{2} \mathrm{O}_{3}$ & 9.96 & 10.0 & 10.1 & 12.3 & 6.97 & 15.9 & 14.3 & 6.42 & 15.0 \\
\hline $\mathrm{CaO}$ & 0.02 & 0.01 & 0.02 & $<0.01$ & 0.18 & 0.05 & $<0.01$ & 0.09 & 0.01 \\
\hline $\mathrm{FeO}$ & 29.5 & 28.8 & 28.8 & 28.5 & 30.5 & 30.9 & 28.3 & 32.3 & 31.0 \\
\hline $\mathrm{MgO}$ & 2.83 & 3.54 & 3.40 & 3.91 & 1.88 & 2.87 & 4.08 & 1.51 & 2.40 \\
\hline $\mathrm{MnO}$ & 0.61 & 0.58 & 0.61 & 0.56 & 0.70 & 0.65 & 0.65 & 0.66 & 0.64 \\
\hline $\mathrm{Cr}_{2} \mathrm{O}_{3}$ & 55.8 & 55.9 & 55.7 & 54.1 & 56.8 & 47.4 & 51.1 & 56.5 & 49.3 \\
\hline $\mathrm{TiO}_{2}$ & 0.69 & 0.75 & 0.61 & 0.82 & 0.50 & 0.81 & 0.69 & 1.08 & 0.70 \\
\hline $\mathrm{V}_{2} \mathrm{O}_{3}$ & 0.34 & 0.57 & 0.56 & & 0.56 & 0.40 & & 0.62 & 0.48 \\
\hline Total & 99.7 & 100.2 & 99.2 & 100.3 & 98.3 & 99.0 & 99.1 & 99.4 & 99.5 \\
\hline $\mathrm{Si}$ & 0.00 & 0.00 & 0.00 & 0.00 & 0.01 & 0.01 & 0.00 & 0.01 & 0.00 \\
\hline $\mathrm{Al}$ & 0.82 & 0.82 & 0.82 & 0.99 & 0.59 & 1.28 & 1.15 & 0.55 & 1.21 \\
\hline $\mathrm{Ca}$ & 0.00 & 0.00 & 0.00 & 0.00 & 0.01 & 0.00 & 0.00 & 0.01 & 0.00 \\
\hline $\mathrm{Fe}$ & 1.72 & 1.66 & 1.67 & 1.63 & 1.85 & 1.77 & 1.62 & 1.95 & 1.78 \\
\hline $\mathrm{Mg}$ & 0.29 & 0.36 & 0.35 & 0.40 & 0.20 & 0.29 & 0.42 & 0.16 & 0.25 \\
\hline $\mathrm{Mn}$ & 0.04 & 0.03 & 0.04 & 0.03 & 0.04 & 0.04 & 0.04 & 0.04 & 0.04 \\
\hline $\mathrm{Cr}$ & 3.08 & 3.06 & 3.06 & 2.92 & 3.25 & 2.56 & 2.76 & 3.22 & 2.67 \\
\hline $\mathrm{Ti}$ & 0.04 & 0.04 & 0.03 & 0.04 & 0.03 & 0.04 & 0.04 & 0.06 & 0.04 \\
\hline V & 0.02 & 0.03 & 0.03 & & 0.03 & 0.02 & & 0.04 & 0.03 \\
\hline Total & 6.01 & 6.01 & 6.01 & 6.00 & 6.02 & 6.02 & 6.01 & 6.03 & 6.01 \\
\hline Usp & 1.8 & 2.0 & 1.6 & 2.1 & 1.4 & 2.1 & 1.8 & 3.0 & 1.8 \\
\hline $\mathrm{Sp}$ & 20.6 & 20.7 & 20.9 & 24.7 & 15.2 & 32.6 & 28.9 & 14.1 & 30.6 \\
\hline \multirow[t]{2}{*}{$\mathrm{Chm}$} & 77.5 & 77.4 & 77.5 & 73.1 & 83.4 & 65.3 & 69.4 & 82.9 & 67.5 \\
\hline & A-881944 & A-881944 & Dho 700 & Dho $700^{c}$ & NWA 1877 & Y-74097 & Y-74097 & & \\
\hline $\mathrm{SiO}_{2}$ & 0.11 & 0.03 & 0.05 & 0.07 & $<0.02$ & 0.03 & 0.06 & & \\
\hline $\mathrm{Al}_{2} \mathrm{O}_{3}$ & 5.53 & 19.1 & 14.0 & 14.1 & 7.04 & 7.83 & 14.7 & & \\
\hline $\mathrm{CaO}$ & 0.06 & 0.01 & 0.06 & 0.02 & $<0.01$ & 0.01 & $<0.01$ & & \\
\hline $\mathrm{FeO}$ & 31.0 & 30.7 & 27.5 & 26.9 & 28.8 & 24.8 & 24.9 & & \\
\hline $\mathrm{MgO}$ & 1.49 & 2.86 & 4.66 & 4.84 & 2.88 & 5.98 & 6.49 & & \\
\hline $\mathrm{MnO}$ & 0.67 & 0.59 & 0.58 & 0.73 & 0.67 & 0.58 & 0.52 & & \\
\hline $\mathrm{Cr}_{2} \mathrm{O}_{3}$ & 58.9 & 45.1 & 51.0 & 50.6 & 59.2 & 58.9 & 51.8 & & \\
\hline $\mathrm{TiO}_{2}$ & 0.72 & 0.77 & 0.97 & 0.49 & 0.50 & 0.77 & 0.73 & & \\
\hline $\mathrm{V}_{2} \mathrm{O}_{3}$ & 0.58 & 0.49 & 0.47 & 0.63 & & 0.66 & 0.50 & & \\
\hline Total & 98.5 & 99.2 & 99.3 & 98.4 & 99.0 & 99.6 & 99.7 & & \\
\hline
\end{tabular}


Table 3. (continued)

\begin{tabular}{|c|c|c|c|c|c|c|c|}
\hline & A-881944 & A-881944 & Dho 700 & Dho $700^{c}$ & NWA 1877 & Y-74097 & Y-74097 \\
\hline $\mathrm{Si}$ & 0.01 & 0.00 & 0.00 & 0.00 & 0.00 & 0.00 & 0.00 \\
\hline $\mathrm{Al}$ & 0.47 & 1.51 & 1.12 & 1.14 & 0.59 & 0.64 & 1.15 \\
\hline $\mathrm{Ca}$ & 0.00 & 0.00 & 0.00 & 0.00 & 0.00 & 0.00 & 0.00 \\
\hline $\mathrm{Fe}$ & 1.88 & 1.72 & 1.56 & 1.54 & 1.71 & 1.43 & 1.38 \\
\hline $\mathrm{Mg}$ & 0.16 & 0.28 & 0.47 & 0.49 & 0.31 & 0.62 & 0.64 \\
\hline $\mathrm{Mn}$ & 0.04 & 0.03 & 0.03 & 0.04 & 0.04 & 0.03 & 0.03 \\
\hline $\mathrm{Cr}$ & 3.37 & 2.39 & 2.74 & 2.74 & 3.33 & 3.22 & 2.73 \\
\hline $\mathrm{Ti}$ & 0.04 & 0.04 & 0.05 & 0.03 & 0.03 & 0.04 & 0.04 \\
\hline V & 0.03 & 0.03 & 0.03 & 0.03 & & 0.04 & 0.03 \\
\hline Total & 6.01 & 6.00 & 6.01 & 6.02 & 6.01 & 6.01 & 6.01 \\
\hline Usp & 2.0 & 1.9 & 2.5 & 1.3 & 1.3 & 2.0 & 1.9 \\
\hline $\mathrm{Sp}$ & 12.0 & 38.0 & 28.3 & 29.0 & 14.9 & 16.2 & 29.2 \\
\hline Chm & 86.0 & 60.1 & 69.2 & 69.7 & 83.8 & 81.8 & 69.0 \\
\hline
\end{tabular}

Lindstrom [1993]. These diogenites are characterized by granoblastic textures mostly composed of pyroxene with traces of chromite, silica minerals, and Fe-FeS (Figure 3). The Yamato-A type diogenites show a macroscopic structure where fine-grained areas up to $3 \mathrm{~cm}$ rimmed by the coarsegrained area [Takeda et al., 1981]. In the Y-74097 section (,64-1) we have examined, there are large domains (more than several millimeters) of fine-grained area surrounded by veins of clear coarser-grained area (Figure 3a). Pyroxenes in the coarse-grained areas are clear whereas fine-grained pyroxenes are dusty due to the presence of tiny $(<1-2 \mu \mathrm{m}) \mathrm{FeS}$ inclusions. Large isolated chromites grains (about $0.5 \mathrm{~mm}$ ) are surrounded by rims of clear pyroxene, and contain fine inclusions of $\mathrm{FeS}$ and $\mathrm{Fe}$ metal. Tiny chromite grains (about a few microns) are scattered throughout the section. Thin irregular grains of silica minerals $(<100 \mu \mathrm{m})$ occur interstitially along the coarse-grained veins. Cristobalite and tridymite were identified by Raman spectroscopy. Troilite and minor Fe metal occur as fine inclusions in pyroxene in the fine-grained areas and coarser grains $(\sim 50-200 \mu \mathrm{m})$ in the coarse-grained veins.

\subsubsection{A-87147, A-880785, A-880936, A-881239, A-881526, and A-881944}

[16] These diogenites are typical brecciated monomict diogenites consisting of clasts of orthopyroxenes (up to several $\mathrm{mm}$ ) set in a clastic matrix. Minor minerals ( $<$ a few \%) include chromite, Fe-FeS, augite, plagioclase, and silica minerals. Chromite and $\mathrm{Fe}-\mathrm{FeS}$ occur as isolated grains and tiny crystals along healed cracks. Silica minerals occur as tiny inclusion in orthopyroxene.

\subsection{Mineral Chemistry of Pyroxenes, Olivine, and Spinel Minerals}

[17] The $\mathrm{Mg}^{\prime}$ values of bulk pyroxenes in diogenites studied here vary from 69.8 to 78.1 covering the range of reported diogenites [e.g., Fowler et al., 1994; Beck and McSween., 2010; Shearer et al., 2010] (Figure 4). The ferroan diogenites $\left(\mathrm{Mg}^{\prime}=69.8-70.5\right)(\mathrm{A}-881838$ and $\mathrm{A}-$ 881839) contain orthopyroxene with blebs and thin lamellae of augites indicating that these crystals were inverted from
low-Ca pigeonites [Takeda and Mori, 1985]. Minor element abundances $\left(\mathrm{Al}_{2} \mathrm{O}_{3}, \mathrm{TiO}_{2}\right.$, and $\left.\mathrm{Cr}_{2} \mathrm{O}_{3}\right)$ are within the range of diogenites (Figure 5) but slightly lower than those of $\mathrm{Y}$ 75032 diogenites. The olivine compositions in A-881377, and olivine diogenites, A-881538 and NWA 1877 are limited within individual meteorites. The $\mathrm{Mg}^{\prime}$ of olivine in these diogenites (A-881377: 71.2; A-881548: 76.2; NWA 1877: 71.2) are in the range of known olivine-bearing diogenites $\left(\mathrm{Mg}^{\prime}=73-63\right)$ [e.g., Shearer et al., 2010]. Chromites in A$881388 / 89, \mathrm{~A}-881377$ and A-881944 have large ranges of $\mathrm{Al} / \mathrm{Cr}$ ratios (Figure 6).

[18] Three diogenites, Dho 700, A-881377 and Y-74097 have pyroxenes which are chemically zoned. The orthopyroxene grains in Dho 700 display a normal igneous zoning $\left(\sim \mathrm{Wo}_{2} \mathrm{En}_{69} \mathrm{Fs}_{29}\right.$ to $\left.\sim \mathrm{Wo}_{4} \mathrm{Mg}_{66} \mathrm{Fe}_{30}\right)$. The $\mathrm{Mg}^{\prime}$ values increase gradually toward the cores from the rims $(\sim 68$ to $\sim 71)$. The $\mathrm{CaO}$ abundances decrease toward the cores from $\sim 2 \mathrm{wt} \%$ to $\sim 1 \mathrm{wt} \%$. The $\mathrm{Al}_{2} \mathrm{O}_{3}$ and $\mathrm{TiO}_{2}$ are slightly enriched in the rims compared to the cores $\left(\mathrm{Al}_{2} \mathrm{O}_{3}\right.$ from 0.3 to $0.4 \mathrm{wt} \%$ to 0.9 $1.0 \mathrm{wt} \%$ and $\mathrm{TiO}_{2}$ from $<0.01-0.03 \mathrm{wt} \%$ to $0.1 \mathrm{wt} \%$ ) (Figure 7 ). In Y-74097 pyroxenes, we found prominent chemical zoning $\left(\mathrm{Mg}^{\prime}, \mathrm{CaO}, \mathrm{Al}_{2} \mathrm{O}_{3}\right)$ in the large fine/coarse domains in our section (Figure 3). Takeda et al. [1981] reported the chemical zoning only in the coarse-grained areas. The chemical zoning extends over the entire recrystallized orthopyroxene crystals. The abundances of these elements continuously increase toward the cores with no gaps except near the rims. The presence of chemical zoning indicates that the fine-grained areas were originally single crystals before recrystallization. Original grain boundaries are more fractured than the interiors causing rapid grain growth forming clear coarse-grained rims. The wavy profiles observed near the rims in Dho 700 and Y-74097 pyroxenes could be due to the presence of small augite grains exsolved from the host pyroxene and minor brecciation and recrystallization (for Y-74097) (Figure 3a). Except these features, the $\mathrm{Mg}^{\prime}$ values and minor element abundances of Dho 700 and Y-74097 pyroxenes are broadly correlated. In contrast, in A-881377, minor elements show the same kind of zoning as Dho 700 or Y-74097, but the MgFe zoning is not clear. 
Table 4. Chemical Compositions of Plagioclase and Silica Minerals in Diogenite Studied Here

\begin{tabular}{|c|c|c|c|c|c|}
\hline & \multicolumn{5}{|c|}{ Plagioclase } \\
\hline & A-881377 & A-881377 & A-881838 & Dho 700 & Dho 700 \\
\hline $\mathrm{SiO}_{2}$ & 45.2 & 51.0 & 46.3 & 45.0 & 48.3 \\
\hline $\mathrm{Al}_{2} \mathrm{O}_{3}$ & 34.6 & 31.2 & 34.0 & 35.4 & 32.6 \\
\hline $\mathrm{K}_{2} \mathrm{O}$ & 0.02 & 0.12 & 0.02 & 0.01 & 0.08 \\
\hline $\mathrm{Na}_{2} \mathrm{O}$ & 0.95 & 2.88 & 1.15 & 0.45 & 1.29 \\
\hline $\mathrm{CaO}$ & 18.4 & 15.0 & 18.3 & 19.5 & 17.2 \\
\hline $\mathrm{FeO}$ & 0.35 & 0.21 & 0.31 & 0.54 & 0.77 \\
\hline $\mathrm{MgO}$ & 0.03 & 0.09 & 0.03 & 0.08 & 0.21 \\
\hline $\mathrm{MnO}$ & 0.05 & $<0.03$ & $<0.03$ & $<0.03$ & 0.04 \\
\hline $\mathrm{Cr}_{2} \mathrm{O}_{3}$ & 0.03 & $<0.03$ & $<0.03$ & $<0.03$ & 0.03 \\
\hline $\mathrm{TiO}_{2}$ & 0.03 & $<0.03$ & 0.03 & $<0.03$ & $<0.03$ \\
\hline Total & 99.6 & 100.5 & 100.1 & 100.9 & 100.5 \\
\hline \multicolumn{6}{|c|}{ Oxygen $=8$} \\
\hline $\mathrm{Si}$ & 2.09 & 2.31 & 2.13 & 2.06 & 2.21 \\
\hline $\mathrm{Al}$ & 1.89 & 1.67 & 1.84 & 1.91 & 1.75 \\
\hline $\mathrm{K}$ & 0.00 & 0.01 & 0.00 & 0.00 & 0.00 \\
\hline $\mathrm{Na}$ & 0.08 & 0.25 & 0.10 & 0.04 & 0.11 \\
\hline $\mathrm{Ca}$ & 0.91 & 0.73 & 0.90 & 0.96 & 0.84 \\
\hline $\mathrm{Fe}$ & 0.01 & 0.01 & 0.01 & 0.02 & 0.03 \\
\hline $\mathrm{Mg}$ & 0.00 & 0.01 & 0.00 & 0.01 & 0.01 \\
\hline $\mathrm{Mn}$ & 0.00 & 0.00 & 0.00 & 0.00 & 0.00 \\
\hline $\mathrm{Cr}$ & 0.00 & 0.00 & 0.00 & 0.00 & 0.00 \\
\hline $\mathrm{Ti}$ & 0.00 & 0.00 & 0.00 & 0.00 & 0.00 \\
\hline Total & 5.00 & 4.98 & 5.00 & 5.00 & 4.97 \\
\hline Or & 0.1 & 0.7 & 0.1 & 0.1 & 0.5 \\
\hline $\mathrm{Ab}$ & 8.5 & 25.5 & 10.2 & 4.0 & 11.9 \\
\hline An & 91.3 & 73.8 & 89.7 & 95.9 & 87.6 \\
\hline & \multicolumn{4}{|c|}{ Silica Minerals } & \\
\hline & A-881377 & A-881838 & Dho 700 & Y-74097 & \\
\hline $\mathrm{SiO}_{2}$ & 99.2 & 99.2 & 99.4 & 98.8 & \\
\hline $\mathrm{Al}_{2} \mathrm{O}_{3}$ & 0.36 & 0.39 & 0.17 & 0.58 & \\
\hline $\mathrm{K}_{2} \mathrm{O}$ & 0.08 & 0.02 & 0.04 & 0.03 & \\
\hline $\mathrm{Na}_{2} \mathrm{O}$ & $<0.02$ & $<0.02$ & $<0.02$ & 0.21 & \\
\hline $\mathrm{CaO}$ & 0.16 & 0.20 & 0.06 & 0.15 & \\
\hline $\mathrm{FeO}$ & 0.46 & 0.35 & 0.38 & 0.44 & \\
\hline $\mathrm{MgO}$ & $<0.01$ & $<0.01$ & $<0.01$ & 0.01 & \\
\hline $\mathrm{MnO}$ & 0.03 & $<0.03$ & $<0.03$ & $<0.03$ & \\
\hline $\mathrm{Cr}_{2} \mathrm{O}_{3}$ & $<0.03$ & 0.12 & $<0.03$ & 0.04 & \\
\hline $\mathrm{TiO}_{2}$ & 0.05 & 0.09 & 0.08 & 0.06 & \\
\hline Total & 100.4 & 100.4 & 100.1 & 100.3 & \\
\hline \multicolumn{6}{|c|}{ Oxygen $=8$} \\
\hline $\mathrm{Si}$ & 3.97 & 3.97 & 3.98 & 3.96 & \\
\hline $\mathrm{Al}$ & 0.02 & 0.02 & 0.01 & 0.03 & \\
\hline $\mathrm{K}$ & 0.00 & 0.00 & 0.00 & 0.00 & \\
\hline $\mathrm{Na}$ & 0.00 & 0.00 & 0.00 & 0.00 & \\
\hline $\mathrm{Ca}$ & 0.00 & 0.00 & 0.00 & 0.00 & \\
\hline $\mathrm{Fe}$ & 0.00 & 0.00 & 0.00 & 0.02 & \\
\hline $\mathrm{Mg}$ & 0.01 & 0.01 & 0.00 & 0.01 & \\
\hline $\mathrm{Mn}$ & 0.02 & 0.01 & 0.01 & 0.01 & \\
\hline $\mathrm{Cr}$ & 0.00 & 0.00 & 0.00 & 0.00 & \\
\hline $\mathrm{Ti}$ & 0.00 & 0.00 & 0.00 & 0.00 & \\
\hline Total & 4.02 & 4.02 & 4.01 & 4.03 & \\
\hline
\end{tabular}

\subsection{Inclusions in Dho 700 Pyroxenes}

[19] Two types of inclusions can be defined (types 1 and 2) (Figures $2 \mathrm{~b}$ and $2 \mathrm{c}$ ). Type 1 (Mg-rich) inclusions are mainly composed of olivine and pyroxene with higher $\mathrm{Mg}^{\prime}$ values than those of the host granular orthopyroxene. We found only two type 1 inclusions in two PTSs. One of them (A1M1),
$200 \times 160 \mu \mathrm{m}$ in size, is composed of olivine ( $40 \mathrm{vol} \%)$, pyroxene ( $\sim 40$ vol \%), chromite, Fe metal, FeS, holes (plucked out during PTS preparation?), and weathering products. The $\mathrm{Mg}^{\prime}$ values of olivine in type 1 inclusions are relatively constant at $\sim 71-72$ (Figure 8 ). The pyroxene inside the A1M1 inclusion has relatively constant compositions of $\mathrm{Mg}^{\prime}(\sim 75), \mathrm{CaO}(1.2 \mathrm{wt} \%)$ but the abundances of $\mathrm{Al}_{2} \mathrm{O}_{3}$ $(0.6 \mathrm{wt} \%)$ and $\mathrm{Cr}_{2} \mathrm{O}_{3}(0.17-0.4 \mathrm{wt} \%)$ increase toward the rim. $\mathrm{The} \mathrm{FeO} / \mathrm{MnO}$ ratios ( 23-24) of these inclusions are slightly lower than those of the host pyroxene ( 25-28). The type 1 (Mg-rich) inclusions and the host granular pyroxenes are not equilibrated. The $\mathrm{Mg}^{\prime}$ values of pyroxene increase toward the center of the inclusions (up to 77.9). There is steep compositional gradient across the boundaries between inclusions and the pyroxene host due to partial equilibration (Figure 8). The compositional gradients of $\mathrm{Mg}$ and $\mathrm{Fe}$ in contact with the host pyroxene are anisotropic because the diffusions rates are controlled by crystallographic orientation. The $\mathrm{CaO}$, $\mathrm{Al}_{2} \mathrm{O}_{3}$ and $\mathrm{Cr}_{2} \mathrm{O}_{3}$ contents $(\sim 1.05-1.15,<0.03,<0.03 \mathrm{wt} \%$, respectively) of the inclusions are lower than those of the host pyroxene. The $\mathrm{TiO}_{2}$ contents $(\sim 0.05 \mathrm{wt} \%)$ are similar to those of the host pyroxene.

[20] The type 2 inclusions mainly consist of low-Ca pyroxene with lesser amounts of augite, Fe metal, FeS, silica minerals, and weathering products. We found three type 2 inclusions in one PTS. Type 2 inclusions have low-Ca pyroxene with similar $\mathrm{Mg}^{\prime}$ to the host orthopyroxene. The $\mathrm{Mg}^{\prime}$ values and $\mathrm{CaO}$ contents of low-Ca pyroxene are almost identical to those of the host pyroxenes. The contents of $\mathrm{Cr}_{2} \mathrm{O}_{3}$ and $\mathrm{Al}_{2} \mathrm{O}_{3}$ are $0.1-0.8$ and $0.2-1.0 \mathrm{wt} \%$ respectively and mostly lower than in the host orthopyroxene. The $\mathrm{TiO}_{2}$ contents $(\sim 0.05 \mathrm{wt} \%)$ are similar to those of the host pyroxene and $\mathrm{Mg}$-rich inclusions. On an $\mathrm{Al}_{2} \mathrm{O}_{3}$ and $\mathrm{TiO}_{2}$ diagram, four inclusions plot on the trend of Dho 700 host pyroxene, but some of them have lower $\mathrm{Al}_{2} \mathrm{O}_{3}$ and $\mathrm{TiO}_{2}$ (Figure 5). Augite compositions are $\mathrm{Wo}_{42.9-43.5} \mathrm{En}_{43.8-44.4}$.

[21] The chemical similarities indicate that these inclusions and the host pyroxene are genetically related. The type 1 inclusions are more likely crystals formed from more primitive diogenitic melts (which were certainly genetically linked with Dho 700). It is likely that these inclusions were fragments of early phases from that melt that was parental to this diogenite or were those of diogenites seated in the deep crust.

\section{Discussion}

\subsection{Unequilibrated and Equilibrated Diogenites}

[22] Our observations demonstrate that the subsolidus thermal history of diogenites is variable, and two petrologic types of diogenites can be defined: equilibrated diogenites have homogeneous pyroxenes with respect to major and minor elements whereas unequilibrated diogenites preserve igneous zoning that formed during initial crystallization. Most diogenites are equilibrated in agreement with plutonic origin [e.g., Mittlefehldt, 1994; Beck and McSween, 2010; Shearer et al., 2010]. However, there are at least five diogenites that have chemically zoned pyroxenes: Garland [Fowler et al., 1994], NWA 4215 [Barrat et al., 2006], Dho 700, and Y-74097 (this work). A-881377 pyroxene lacks $\mathrm{Mg}-\mathrm{Fe}$ zoning but has $\mathrm{Ca}$ zoning, indicating this meteorite is an intermediate type. The occurrence of diogenites containing 

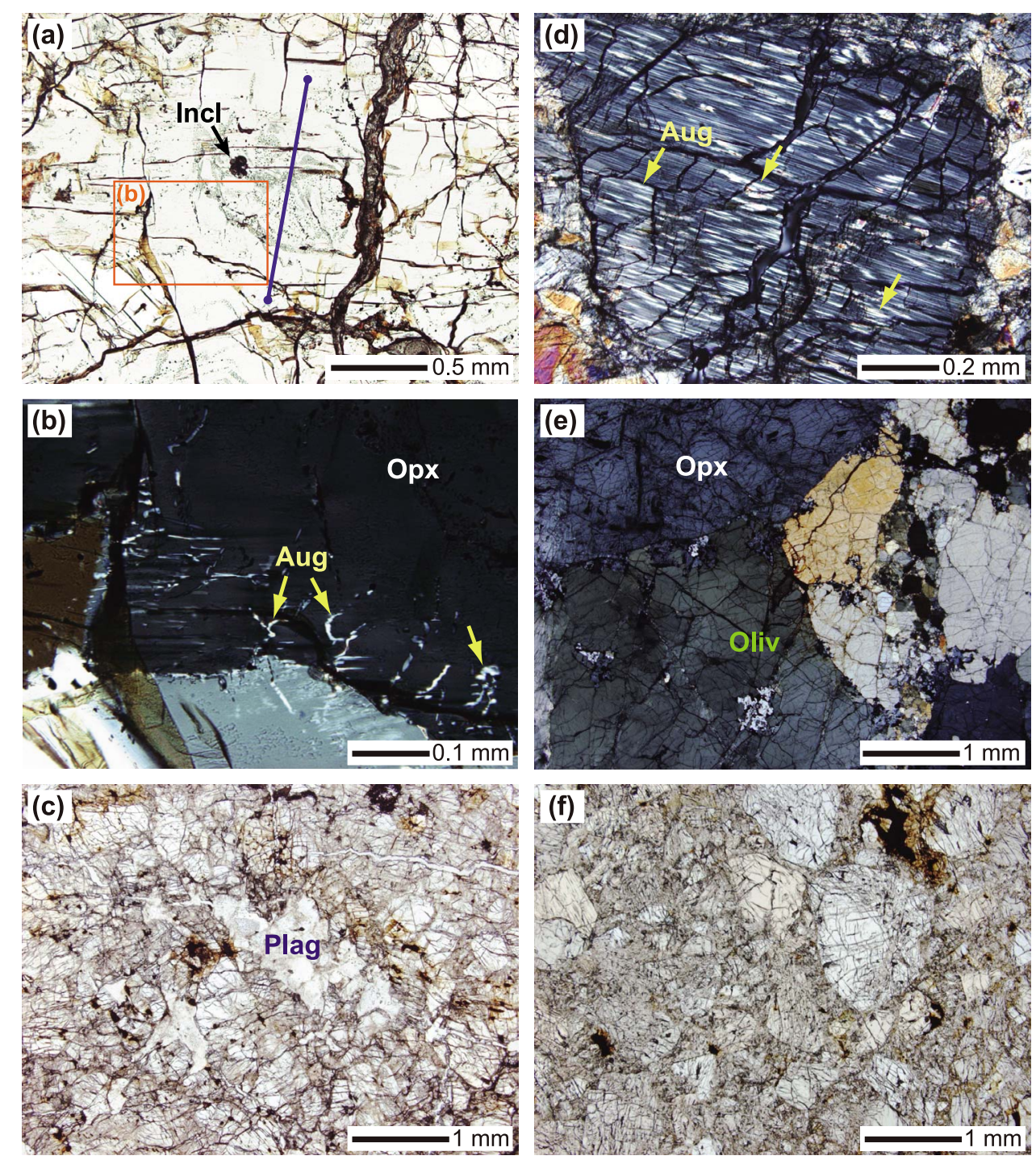

Figure 1. Photomicrographs of diogenites studied here. (a) Overview of Dho 700 showing a granular texture. Note the presence of $\mathrm{Mg}$-rich inclusion (Incl). Blue line refers to locations for compositional profiles in Figure 7a. Plane light. (b) Enlarged view in the orange box in Figure 1a. Thin worms and blebs of augite (Aug) located the rim of orthopyroxene (Opx). Crossed polarized view. (c) Overview of A-881839. There are assemblages of plagioclase grains (the middle). (d) Inverted pigeonite in A-881839. Blebs and lamellae of augite (Aug) set in orthopyroxene host. Crossed polarized view. (e) Olivine diogenite, A-881548. Crossed polarized view. (f) Overview of A-881377. Plane light.

zoned pyroxenes argues against a very slow cooling at depth as expected for the magma ocean cumulates.

[23] Pyroxenes in Dho 700 and Y-74097 have prominent chemical zoning of $\mathrm{Mg}^{\prime}, \mathrm{CaO}$, and $\mathrm{Al}_{2} \mathrm{O}_{3}$ from cores to rims (Figures 3 and 7). A-881377 has similar zonings of $\mathrm{CaO}$ and $\mathrm{Al}_{2} \mathrm{O}_{3}$ in pyroxene while the $\mathrm{Mg}^{\prime}$ zoning is not clear. There are three possible causes of the chemical zoning: Fe metasomatism [Mittlefehldt and Lindstrom, 1997; Barrat et al., 2011], interaction with trapped liquid, and rapid cooling during initial crystallization of magma [e.g., Fowler et al., 1994]. Correlation among $\mathrm{Mg}^{\prime}, \mathrm{CaO}$, and $\mathrm{Al}_{2} \mathrm{O}_{3}$ rules out the possibility that Dho 700 and Y-74097 suffered from Fe metasomatism as seen in unequilibrated eucrites [Barrat et al., 2011]. Interaction of trapped liquid seems unlikely. The composition profiles are continuous with no diffusion bands near the rims (Figure 7). The scarcity of plagioclase (in Dho 700, Y-74097 and A-881377) and the bulk trace element abundances of these diogenites indicate almost no trapped liquids in these diogenites [Barrat et al., 2008, 2010; this study]. Thus, we suggest that the chemical zonings in pyroxene were produced during crystallization from the melts. The relationships between $\mathrm{Ca}, \mathrm{Al}$ and $\mathrm{Mg}^{\prime}$ values are consistent with igneous crystallization; similar chemical zonings are observed in unequilibrated basaltic eucrites [Pun and Papike, 1996]. The presence of the Mg-rich inclusions with steep compositional gradient in the cores of pyroxenes (Figures 2 and 7) strongly argues that Dho 700 cooled rapidly.

[24] Although Y-74097 was crushed by shock and recrystallized, this meteorite still preserves the evidence of original igneous texture. We found continuous, chemical 

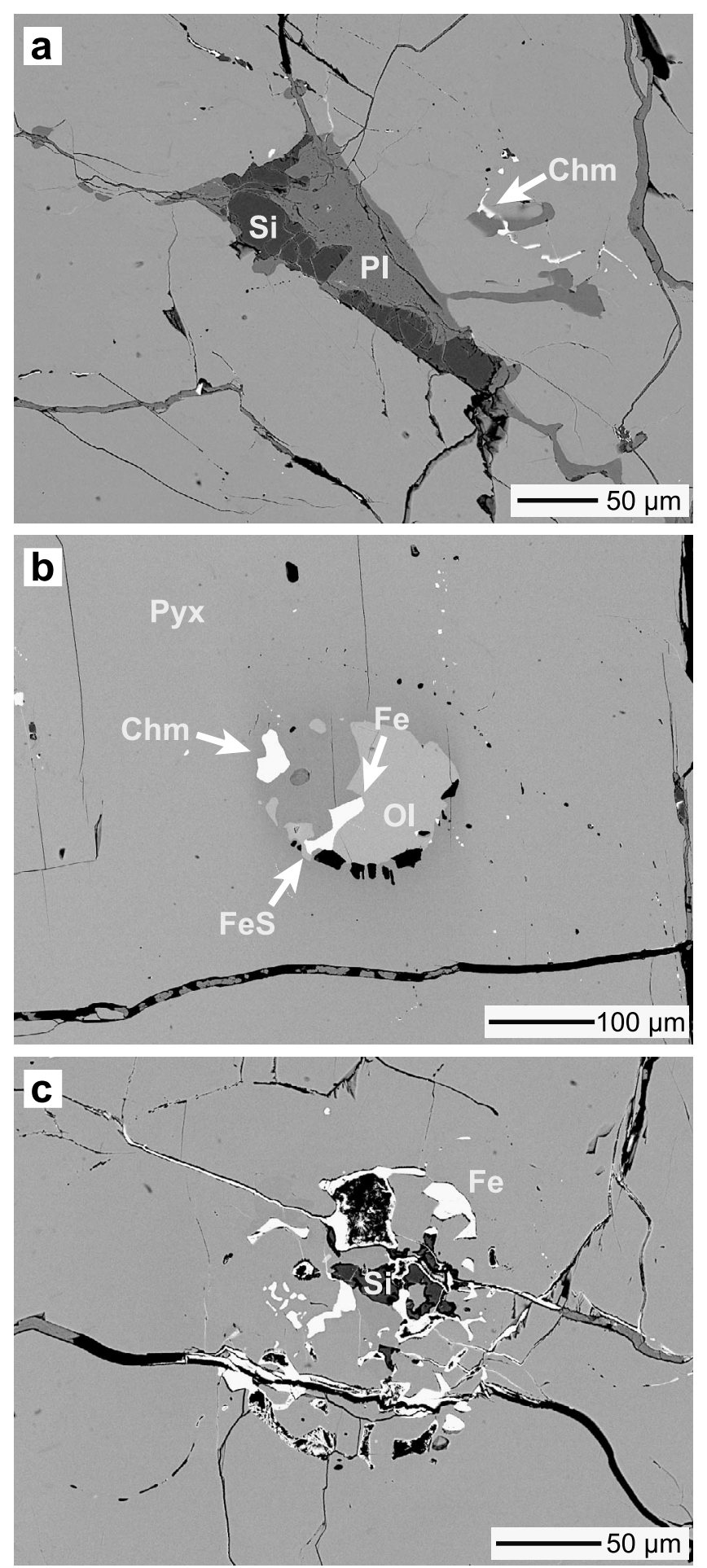

Figure 2. Backscattered electron images of Dho 700 . (a) Silica minerals (tridymite and cristobalite) (Si) and plagioclase $(\mathrm{Pl})$ interstitially occur between pyroxene grains. Tiny elongated inclusions of chromite (Chm) occur. (b) Type 1 (Mg-rich) inclusion (see Figure 1a) composed of olivine (Ol), pyroxene, chromite (Chm), FeS, and Fe metal. (c) Type 2 inclusion in Dho 700, composed of pyroxene, Fe metal, and silica minerals.

zoning from the center of the fine-grained portions to clear veins of coarse-grained material (Figures 3 and $7 b$ ). The zoning pattern is similar to that found in Dho 700 pyroxenes. The observed chemical zoning indicates that the domains are relicts of large zoned single pyroxene crystals. The shock and thermal events that recrystallized orthopyroxenes were not strong enough to wipe out the original igneous zoning.

[25] The cooling rates of the unequilibrated diogenites are not easy to constrain. In the case of Dho 700, an estimation is possible from the compositional profiles of $\mathrm{Mg}^{\prime}$ across the
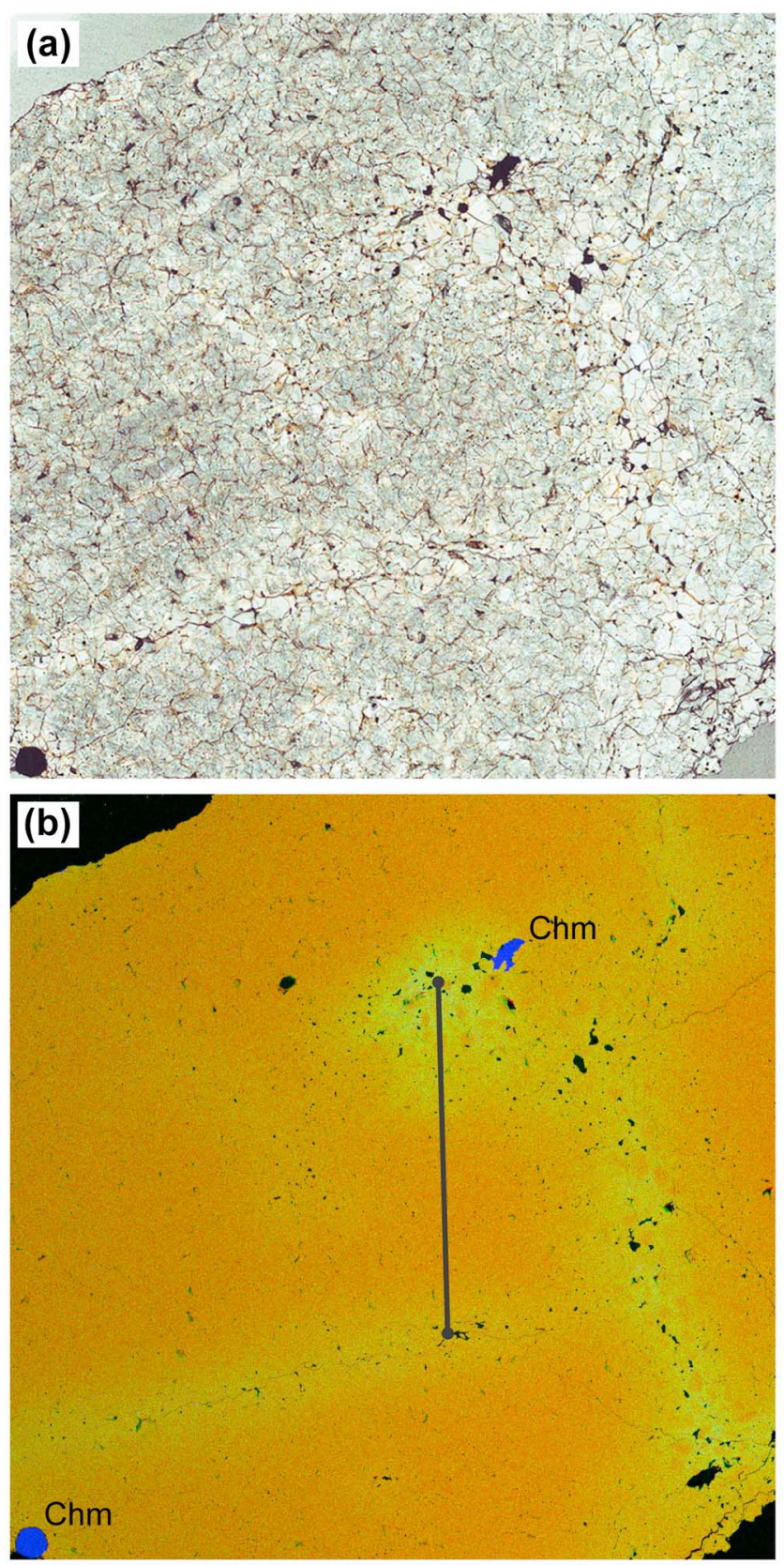

Figure 3. (a) Photomicrograph and (b) combined X-ray map of Y-74097 of the same area. $\mathrm{Mg}$, red; $\mathrm{Ca}$, green; and Al, blue. Y-74097 is a finely recrystallized rock (Figure 3a) but has clear remnant igneous zoning (Figure 3b). Black line in Figure $3 b$ refers to locations for compositional profiles in Figure $7 \mathrm{~b}$. Width is $1 \mathrm{~cm}$. 


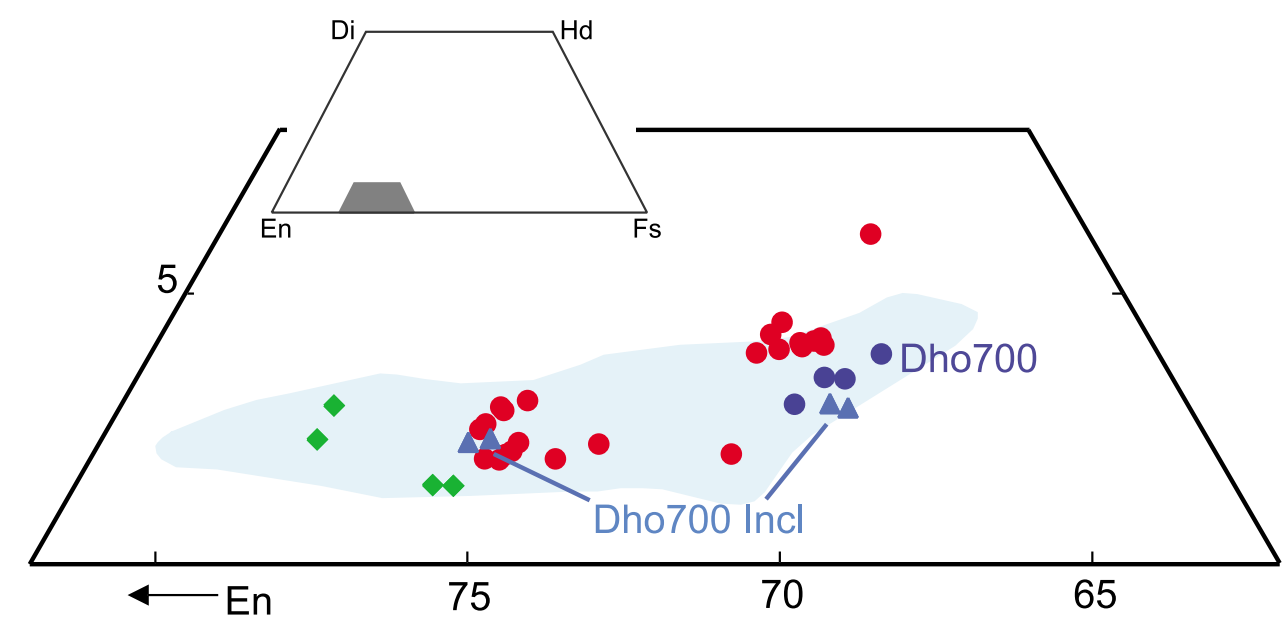

Figure 4. Portion of pyroxene quadrilateral for average compositions of pyroxene. Blue circles and triangles, Dho 700; green diamonds, olivine diogenites; and red circles, other diogenites studied here. Shaded area (light blue) represents the compositional range of other diogenites [Mittlefehldt, 1994; Fowler et al., 1994; Beck and McSween, 2010; Shearer et al., 2010].

boundary between the Mg-rich inclusion and host pyroxene (Figure 9). Since the Mg-rich inclusion is located near the core of the host pyroxene, the inclusion was trapped at the early stage of initial crystallization from the melt. Thus, the cooling rates estimated from the profile provide the lower limit of the initial cooling rate. Cooling rate calculations were made assuming a homogeneous sphere in a compositional homogeneous medium [Crank, 1975]. We used the interdiffusion coefficients of Fe-Mg in orthopyroxene along the $c$ and $b$ directions [Ganguly and Tazzoli, 1994]. We chose the initial temperature of $1250^{\circ} \mathrm{C}$ that corresponds to the approximate liquidus temperature of eucrites [e.g., Stolper, 1977; Righter and Drake, 1997]. It should be noted that the nature of parent melts is not well known and the liquidus temperatures could have been higher in inferred parent magmas of diogenites (e.g., highly pyroxene-normative magmas or boninitic magmas [Mittlefehldt, 1994; Barrat, 2004; Barrat et al., 2008]). The cooling rate of Dho 700 is estimated to be several hundred ${ }^{\circ} \mathrm{C} / \mathrm{yr}$ (Figure 9). The cooling rate is slower than that of an unequilibrated diogenite, NWA $4215\left(10-50^{\circ} \mathrm{C} / \mathrm{yr}\right.$ from $\left.\sim 1200^{\circ} \mathrm{C}\right)$ using a different technique [Barrat et al., 2006]. Cooling rates of other unequilibrated diogenites can be estimated by comparison with the chemical zoning in Dho 700 pyroxene. The original crystal sizes of Y-74097 pyroxene are several times larger than those of Dho 700. Using a relationship $\mathrm{x}^{2}=\mathrm{Dt}$ [Crank, 1975], the

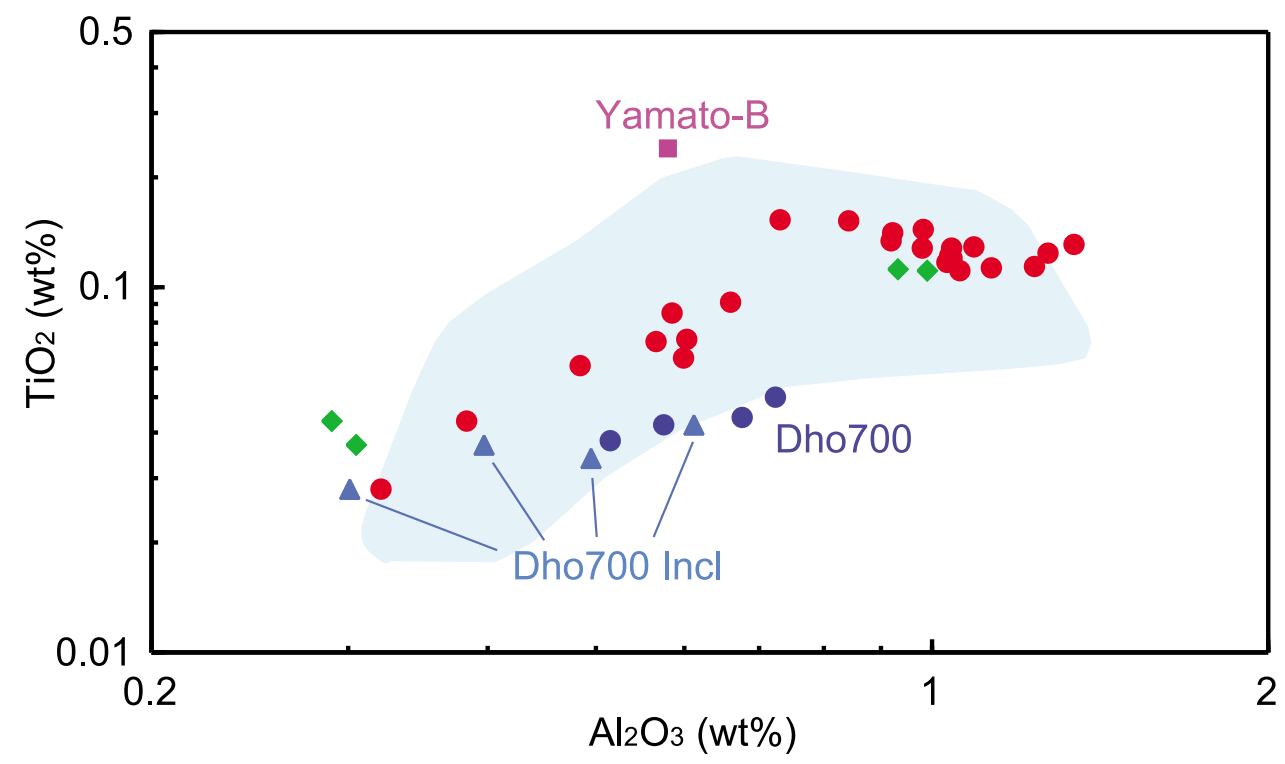

Figure 5. $\mathrm{Al}_{2} \mathrm{O}_{3}$ versus $\mathrm{TiO}_{2}$ for average pyroxenes from diogenite studied here. Blue circles and triangles, Dho 700; green diamond, olivine diogenites; and red circle, other diogenites studied here. Shaded area (light blue) represents the compositional range of other diogenites [Mittlefehldt, 1994; Fowler et al., 1994; Beck and McSween, 2010]. "Yamato-B" refers to a composition of Yamato-75032 type diogenites (Type B) [Mittlefehldt and Lindstrom, 1993]. 
(a) Dho 700

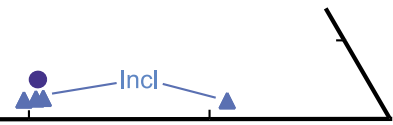

(b) A-881838/39

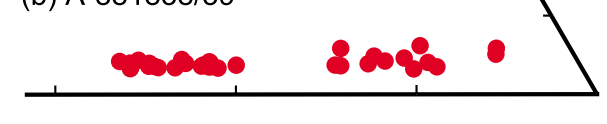

(c) Olivine diogenites

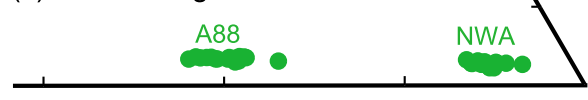

(d) A-881377

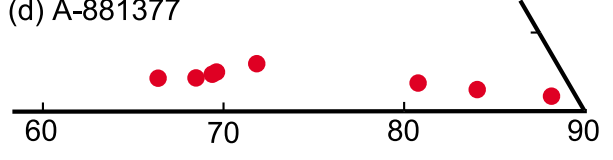

(e) A-881944

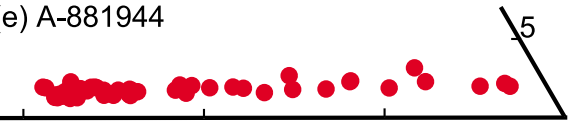

(f) Y-74097
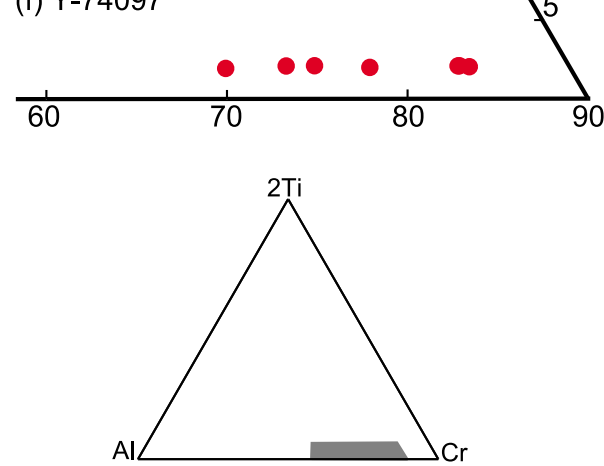

Figure 6. Spinel compositions plotted in part of the spinel triangle.

cooling rates of Y-74097 during initial crystallization would have been an order of magnitude slower. These estimated cooling rates are much faster than those expected for cumulate rocks (e.g., $1.6-6 \times 10^{-4} \circ \mathrm{C} / \mathrm{yr}$ [Miyamoto and Takeda, 1994]).

[26] Thus, the thermal histories of diogenites are similar to those of the basaltic eucrites which display some unequilibrated specimens and others well equilibrated [e.g., Reid and Barnard, 1979; Takeda and Graham, 1991;
Yamaguchi et al., 1996]. The presence of Fe-Mg zoning in pyroxene indicates that metamorphic grades of Dho 700, Y-74097, NWA 4215 and Garland could be comparable to those of type 1-3 basaltic eucrites (type 1-3) but certainly lower than those of type 5-6 eucrites [Takeda and Graham, 1991]. The A-881377 pyroxene shows Ca zoning but lacks Fe-Mg zoning, indicating the metamorphic degree comparable to type 4 eucrites (e.g., Stannern) [Takeda and Graham, 1991]. Thus, the subsolidus cooling rates of these diogenites
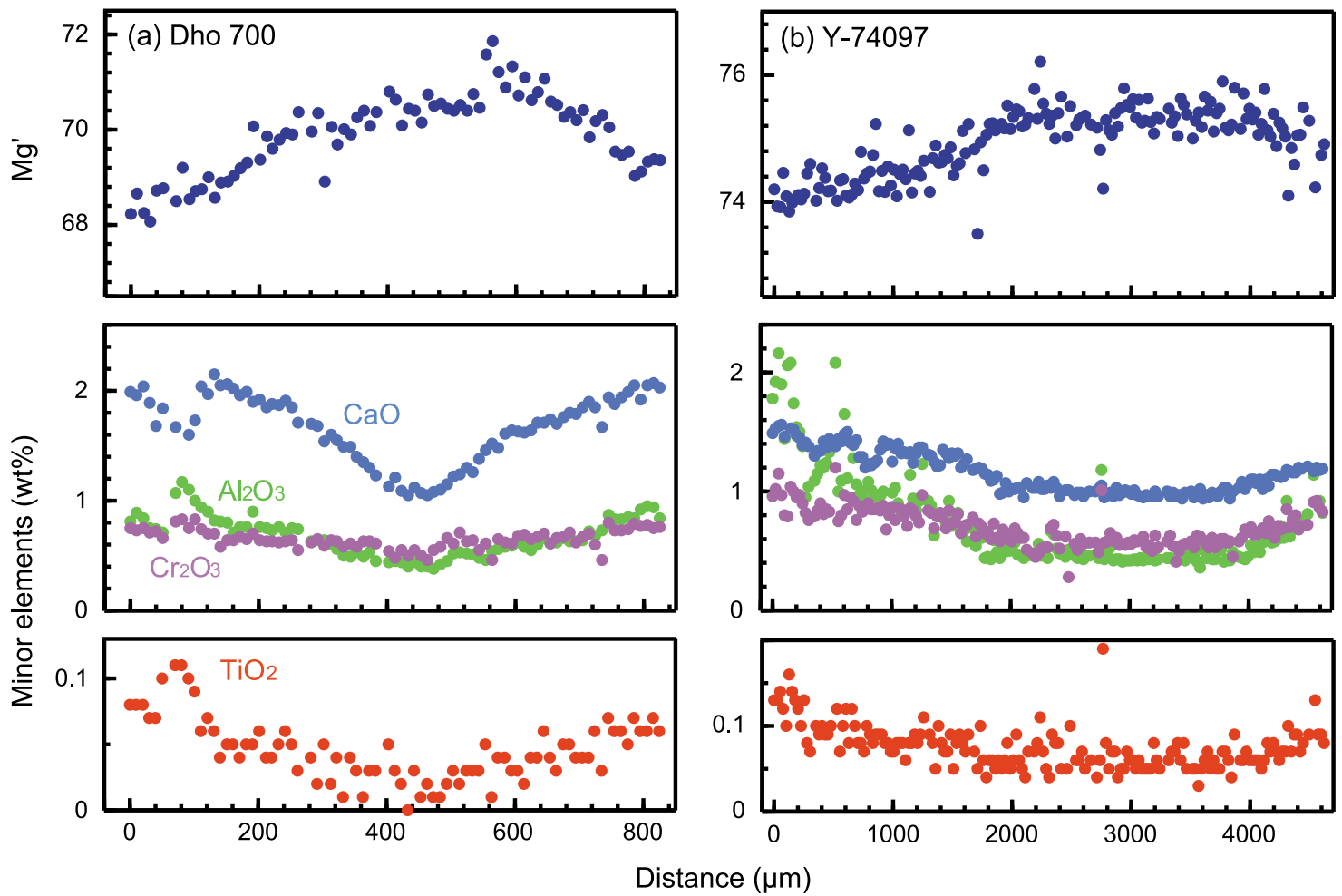

Figure 7. Compositional profiles of chemically zoned pyroxenes from (a) Dho 700 and (b) Y-74097. Pyroxenes from these diogenites show similar chemical zoning. The locations of these profiles of Figures $7 \mathrm{a}$ and $7 \mathrm{~b}$ are shown in Figure $1 \mathrm{~b}$ and $3 \mathrm{~b}$, respectively. 

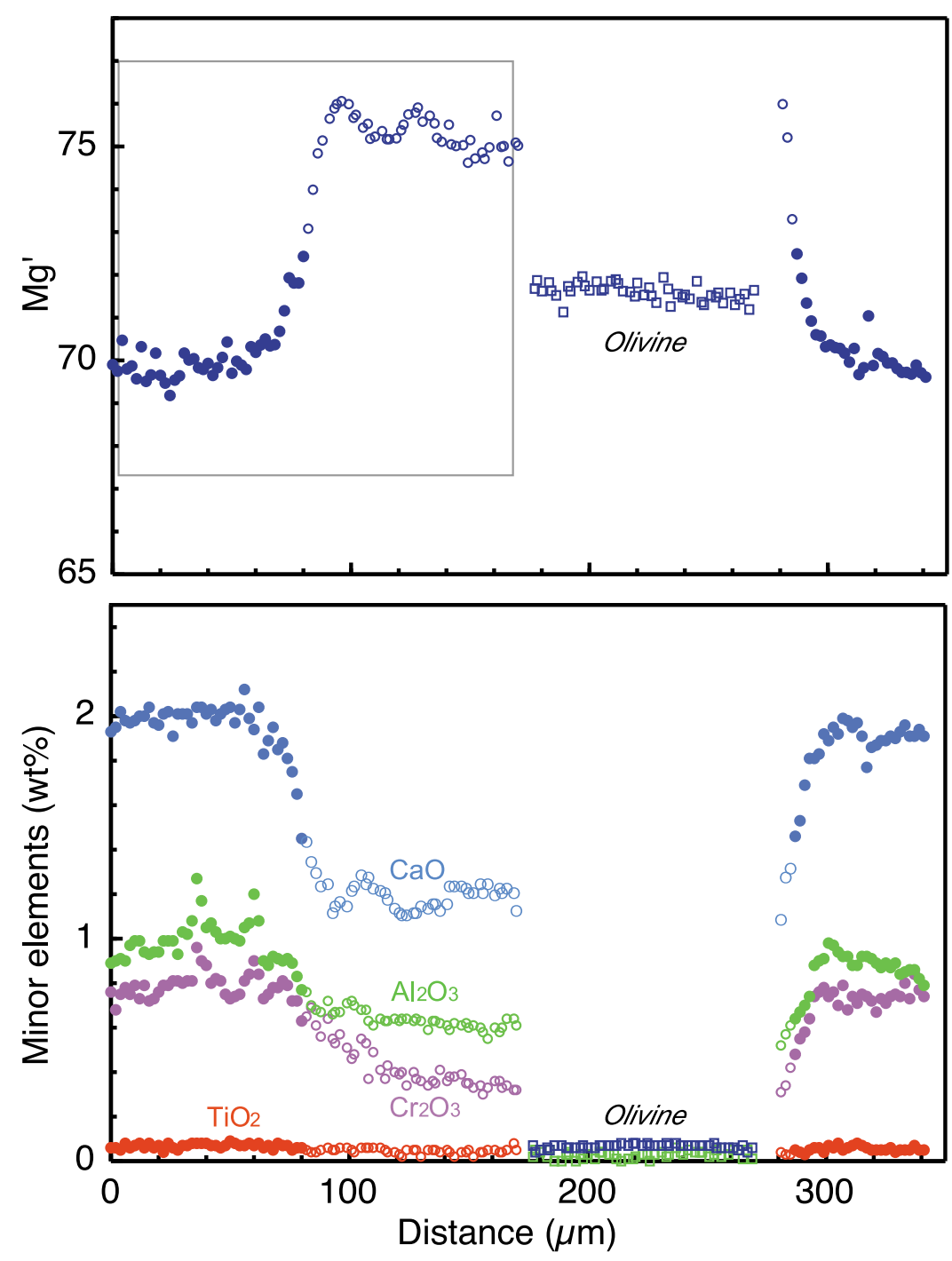

Figure 8. Compositional profiles across the type 1 (Mg-rich) inclusion (A1-M1) (see Figure 2b). Solid circles, pyroxene in the host; open circles, pyroxene in the inclusion; open squares, olivine in the inclusion.

are much faster than those of type 5-6 eucrites. The rapid cooling rates imply that these diogenites were emplaced in a crust or extruded on the surface. On the other hand, cooling rates of equilibrated diogenites during crystallization are not known, but certainly much slower than those of unequilibrated eucrites and diogenites.

[27] The subsolidus equilibration temperatures were estimated from two-pyroxene and spinel-orthopyroxene geothermometers which can be applied for most of the diogenites studied here. The lowest $\mathrm{Ca}$ contents in orthopyroxenes in the equilibrated diogenites imply very low equilibration temperatures at $\sim 600-700^{\circ} \mathrm{C}$ [Lindsley, 1983]. The closure temperatures of $\mathrm{Fe}^{2+}-\mathrm{Mg}$ exchange between spinel and orthopyroxene [Hermann and Ganguly, 2001] of unequilibrated diogenites (Dho 700 and Y-74097) are relatively high from 870 to $1190^{\circ} \mathrm{C}$ probably suggesting rapid cooling from the melts. In contrast, the temperatures of equilibrated diogenites range from 480 to $920^{\circ} \mathrm{C}$ which is similar to those of other diogenites [e.g., Mittlefehldt 1994; Hermann and Ganguly, 2001; Shearer et al., 2010]. The wide range of the equilibration temperatures of the equilibrated diogenites suggests excavation of diogenites after slow cooling in the depths [e.g., Hermann and Ganguly, 2001]. The subsolidus thermal history of diogenite is similar to that of basaltic eucrites [e.g., Yamaguchi et al., 1996, 2001].

[28] Our data show that and the thermal histories, the textural features, and the chemical features are certainly not linked. Barrat et al. [2008, 2010] classified the diogenites studied here into distinct chemical groups. An unequilibrated diogenite, Y-74013 and equilibrated diogenites. A-880785 and A-880936 are in the same chemical group. Although A-87147 and A-881377 have similar REE patterns, their textures and mineralogy are very different. A-87147 is a typical brecciated and equilibrated diogenite. A- 881377 is an olivine-bearing, unequilibrated diogenite. A-881548 is an olivine diogenite but displays a REE pattern similar to the Johnstown diogenite. We suggest that diogenite plutons with variable chemical compositions were emplaced at various depths in the eucritic crust. 


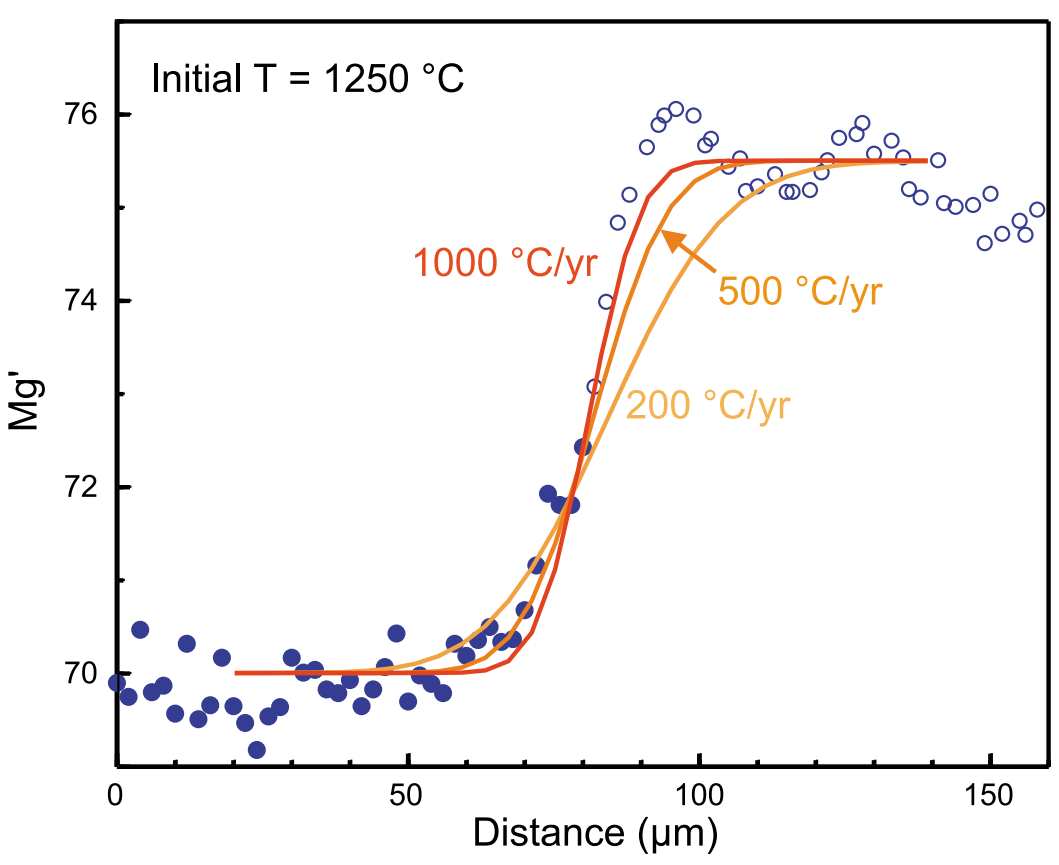

Figure 9. Enlarged view of box in Figure 8 (top) across the boundary between host pyroxene and inclusion. The calculated diffusion profiles are compared (see the text for more details).

\subsection{Formation of Vestan Crust: Postmagma Ocean Magmatism}

[29] Several lines of geochemical and isotopic evidence strongly suggest that the differentiation of Vesta was triggered by a magma ocean in its early history [Hewins and Newsom, 1988; Righter and Drake, 1997; Greenwood et al., 2005]. In the magma ocean model, eucrites were residual liquids after extensive fractional crystallization, and diogenites were cumulate rocks accumulated beneath the magma ocean [e.g., Righter and Drake, 1997; Takeda, 1997; Warren, 1997]. If this view is correct, at least three conditions should be fulfilled by the various eucritic and diogenitic lithologies: first, crystallization ages of diogenites should be as old or slightly older than those of eucrites; second, eucrites and diogenites should have formed from the same parental melts; third, all the diogenites should have been located in the parent body at a deep structural level, certainly below the eucritic crust, and consequently should display metamorphic reequilibration at least as severe as those of the most metamorphosed eucrites.

[30] The compositional trends of pyroxenes form HED cumulates form a single line for major elements, and have been interpreted as an evidence of crystallization of the various HED lithologies from a single magma (magma ocean) [Takeda, 1997]. On the other hand, the increasing diversity of diogenites revealed by recent finds from hot or cold deserts has challenged this point of view. First, the minor and trace element abundances indicate that diogenites crystallized from multiple magmatic bodies [Mittlefehldt, 1994; Fowler et al., 1994; Barrat et al., 2008, 2010; Shearer et al., 2010]. Interestingly, some diogenites (e.g., Tatahouine) formed from heavy rare earth element enriched melts which could have been produced by the remelting of some cumulates lithologies [e.g., Fukuoka et al., 1977] likely some magma ocean cumulates [Barrat, 2004; Barrat et al., 2008]. Furthermore, the deep negative Eu anomalies displayed by some diogenitic orthopyroxenes suggest that the parental magmas of some diogenites were contaminated by melts derived by partial melting of eucrites [Barrat et al., 2010]. Thus, it can be inferred that parental melts of some diogenites intruded the eucritic crust, and consequently are younger than eucrites.

[31] The presence of unequilibrated diogenites strengthens this conclusion. Unequilibrated diogenites crystallized rapidly and escaped from the later global crustal metamorphism [Yamaguchi et al., 1996, 1997]. Thus, these rocks are not explained by a simple layered model of the Vestan crust [e.g., Takeda, 1997]. The presence of these diogenties supports the model that diogenite represent lithologies from multiple plutions in the crust [Mittlefehldt, 1994, 2000; Shearer et al., 2010]. It is possible that diogenites and eucrites occur as neighbors in the crust consistent with the fact that diogenites and eucrites occur together in the same breccias. Furthermore, the unequilibrated diogenites provide an additional hint to the relative chronology of diogenites. If all the types of eucrites and diogenites formed in similar crustal settings, crystallization of unequilibrated diogenites has necessarily postdated the formation of equilibrated eucrites. Thus, the view that diogenites are magma ocean cumulates cannot be maintained. Petrological and geochemical data strongly suggest that diogenitic magmatism was posteucritic (Figure 10), and could have caused significant effects on the early formed eucritic crust with respect to its composition, thermal history and structure. Indeed, multiple intrusions of diogenitic plutons could have supplied heat for global crustal metamorphism of the Vestan crust, and possibly locally the partial melting of the crust [Yamaguchi et al., 1996, 1997, 2001, 2009; Barrat et al., 2007, 2010]. These intrusions caused perturbations of the trace element geochemistry of the 


\section{Stage I. Formation of layered structure}

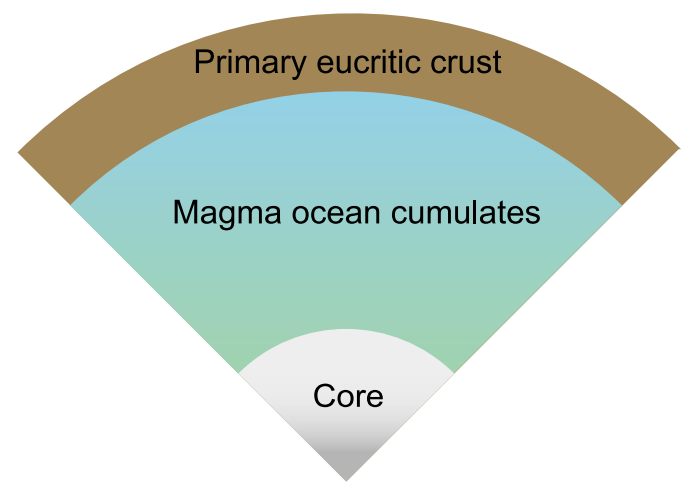

Stage 2. Post-magma ocean volcanism

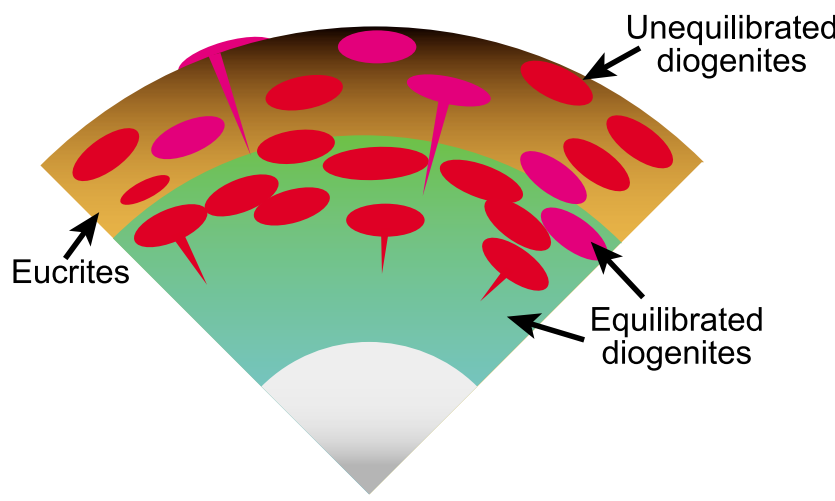

Figure 10. Temporal evolution of the structure of the Vestan crust. Vesta was initially covered by a magma ocean. Its oldest crust is eucritic and formed chiefly from an accumulation of lava flows and related intrusions. The diogenitic magmatism is younger and was probably generated by the remelting of the magma ocean cumulates. The cause of the remelting is not yet understood (overturn of the cumulate pile?). Multiple batches of diogenitic parental melts intruded the early formed eucritic crust. Whereas many diogenites formed intrusions or plutons in the lower eucritic crust, some of diogenitic parental melts intruded near the surface or possibly extruded on the parent body surface to form unequilibrated diogenites (e.g., Dho 700).

country rocks as well as widespread resetting of some radiogenic ages [e.g., Yamaguchi et al., 2001].

[32] Our model (as well as that of Barrat et al. [2010]) predicts that Vestan geology is more complicated that inferred from a simple layered crust model [e.g., Takeda, 1979, 1997]. In addition, intrusions of diogenites would have significantly reorganized the primary eucritic crust. Using the mass balance of $\mathrm{FeO}, \mathrm{MgO}$ and $\mathrm{Al}_{2} \mathrm{O}_{3}$ abundances, Delaney [1995] estimated the thicknesses of layers of eucrites and diogenites are $25 \mathrm{~km}$ and $40 \mathrm{~km}$ respectively. Although these values are strongly model dependent, we suggest that the crust of Vesta is a complicated combination of eucrites and diogenites, that could be much thicker than $60 \mathrm{~km}$ if all diogenites formed in intrusions located within the primary eucritic crust. Subsequently, the crust was heavily cratered by impacts. Thus, we infer that diogenite spots appear as the centers of impact craters as well as exposed rocks on the surface, and that the deep-seated dunite layer assumed by the geochemical models [Righter and Drake, 1997; Ruzicka et al., 1997] would thus hardly be excavated by impacts, even by the event that produced the large South Pole basin.

\section{Conclusions}

[33] We studied petrology and geochemistry of 13 diogenites to better understand the formation processes of Vestan crust. Diogenites are here classified into two petrologic types: equilibrated and unequilibrated diogenites. Unequilibrated diogenites preserve original chemical zoning produced by initial crystallization; they cooled rapidly from melts and escaped metamorphism; in contrast, equilibrated diogenites have pyroxene with homogeneous major element compositions. They crystallized rapidly and were subsequently strongly metamorphosed, or alternatively they cooled slowly in the deep crust. The degrees of metamorphism in unequilibrated diogenites are lower than those of equilibrated eucrites. The thermal history of diogenites supports the idea that diogenitic parental melts formed later and intruded the early formed eucritic crust. The diogenitic magmatism may have caused chemical alteration of eucrites and diogenite magmas, and bring additional heat for global crustal metamorphism. Diogenite intrusions into the eucritic crust significantly thickened the crust, which made it difficult to excavate olivine mantle of Vesta by moderate impacts.

[34] Acknowledgments. This research was partly supported by a Grant-in-Aid for Scientific Research from the Ministry of Education, Science, and Technology, Japan, 19540511 (A.Y.) and NIPR, Research Project Funds, KP-6 and was initiated while one of the authors (A.Y.) visited UBO in Brest. We thank the Associate Editor, D.W Mittlefehldt, and an anonymous reviewer for constructive reviews, and R. Hewins for discussion and improvement of the English.

\section{References}

Barrat, J. A. (2004), Determination of the parental magmas of HED cumulates: The effects of interstitial melts, Meteorit. Planet. Sci., 39, 1767-1779, doi:10.1111/j.1945-5100.2004.tb00074.x.

Barrat, J. A., P. Beck, M. Bohn, J. Cotten, P. Gillet, R. C. Greenwood, and I. A. Franchi (2006), Petrology and geochemistry of the fine-grained, unbrecciated diogenite northwest Africa 4215, Meteorit. Planet. Sci., 41, 1045-1057, doi:10.1111/j.1945-5100.2006.tb00503.x.

Barrat, J. A., A. Yamaguchi, R. C. Greenwood, M. Bohn, J. Cotten, M. Benoit, and I. A. Franchi (2007), The Stannern trend eucrites: Contamination of main-group eucritic magmas by crustal partial melts, Geochim. Cosmochim. Acta, 71, 4108-4124, doi:10.1016/j.gca.2007.06.001.

Barrat, J. A., A. Yamaguchi, M. Benoit, J. Cotten, and M. Bohn (2008), Geochemistry of diogenites: Still more diversity in their parental melts, Meteorit. Planet. Sci., 43, 1759-1775, doi:10.1111/j.1945-5100.2008. tb00641.x.

Barrat, J. A., A. Yamaguchi, B. Zanda, C. Bollinger, and M. Bohn (2010), Relative chronology of crust formation on asteroid Vesta: Insights from the geochemistry of diogenites, Geochim. Cosmochim. Acta, 74, 6218-6231, doi:10.1016/j.gca.2010.07.028.

Barrat, J. A., A. Yamaguchi, T. E. Bunch, M. Bohn, C. Bollinger, and G. Ceuleneer (2011), Possible fluid-rock interactions on differentiated asteroids recorded in eucritic meteorites, Geochim. Cosmochim. Acta, 75, 3839-3852, doi:10.1016/j.gca.2011.04.013.

Beck, A. W., and H. Y. McSween (2010), Diogenites as polymict breccias composed of orthopyroxene and harzburgite, Meteorit. Planet. Sci., 45, 850-872, doi:10.1111/j.1945-5100.2010.01061.x.

Binzel, R. P., and S. Xu (1993), Chips off of asteroid 4 Vesta: Evidence for the parent body of basaltic achondrite meteorite, Science, 260, 186-191, doi:10.1126/science.260.5105.186.

Binzel, R. P., M. J. Gaffey, P. C. Thomas, B. H. Zellner, A. D. Storrs, and E. N. Wells (1997), Geological mapping of Vesta from 1994 Hubble 
Space Telescope images, Icarus, 128, 95-103, doi:10.1006/icar.1997. 5734.

Crank, J. (1975), The Mathematics of Diffusion, 414 pp., Oxford Univ. Press, New York.

Delaney, J. S. (1995), 4 Vesta: A thick-skinned parent for basaltic achondrite, Lunar Planet. Sci., XXVI, 329-330.

Fowler, G. W., J. J. Papike, C. K. Shearer, and M. N. Spilde (1994), Diogenites as asteroidal cumulates. Insights from orthopyroxene major and minor element chemistry, Geochim. Cosmochim. Acta, 58 , 3921-3929, doi:10.1016/0016-7037(94)90371-9.

Fowler, G. W., J. J. Papike, M. N. Spilde, and C. K. Shearer (1995), Diogenites as asteroidal cumulates: Insights from orthopyroxene trace element chemistry, Geochim. Cosmochim. Acta, 59, 3071-3084, doi:10.1016/0016-7037(95)00196-4.

Fukuoka, T., W. V. Boynton, M. S. Ma, and R. A. Schmitt (1977), Genesis of howardites, diogenites and eucrites, Proc. Lunar Sci. Conf., 8 , $187-210$.

Gaffey, M. J. (1997), Surface lithologic heterogeneity of asteroid 4 Vesta, Icarus, 127, 130-157, doi:10.1006/icar.1997.5680.

Ganguly, J., and V. Tazzoli (1994), $\mathrm{Fe}^{2+}-\mathrm{Mg}$ interdiffusion in orthopyroxene: Retrieval from the data on intracrystallizne exchange reaction, Am. Mineral., 79, 930-937.

Greenwood, R. C., I. A. Franchi, A. Jambon, and P. C. Buchanan (2005), Widespread magma oceans on asteroidal bodies in the early solar system, Nature, 435, 916-918, doi:10.1038/nature03612.

Hermann, H.-P., and J. Ganguly (2001), Compositional properties of coexisting orthopyroxene and spinel in some Antarctic diogenites: Implications for thermal history, Meteorit. Planet. Sci., 36, 155-166, doi:10.1111/j.1945-5100.2001.tb01816.x.

Hewins, R. H., and H. E. Newsom (1988), Igneous activity in the early solar system, in Meteorites and the Early Solar System, edited by J. F. Kerrige and M. S. Matthews, pp. 73-101, Univ. of Ariz. Press, Tucson.

Lindsley, D. H. (1983), Pyroxene thermometry, Am. Mineral., 68, 477-493.

Mason, B. (1962), Meteorites, John Wiley, New York.

McCord, T. B., J. B. Adams, and T. V. Johnson (1970), Asteroid Vesta: Spectral reflectivity and compositional implications, Science, 168 1445-1447, doi:10.1126/science.168.3938.1445.

Mittlefehldt, D. W. (1994), The genesis of diogenites and HED parent body petrogenesis, Geochim. Cosmochim. Acta, 58, 1537-1552, doi:10.1016/ 0016-7037(94)90555-X

Mittlefehldt, D. W. (2000), Petrology and geochemistry of the Elephant Moraine A79002 diogenite: A genomict breccia containing a magnesian harzburgite component, Meteorit. Planet. Sci., 35, 901-912, doi:10.1111/ j.1945-5100.2000.tb01479.x.

Mittlefehldt, D. W., and M. M. Lindstrom (1993), Geochemistry and petrology of a suite of ten Yamato HED meteorites, Proc. NIPR Symp. Antarct. Meteorites, 6, 268-292.

Mittlefehldt, D. W., and M. M. Lindstrom (1997), Magnesian basalt clasts from the EET 92014 and Kapoeta howardites and a discussion of alleged primary magnesian HED clasts, Geochim. Cosmochim. Acta, 61 453-462, doi:10.1016/S0016-7037(96)00357-2.

Miyamoto, M., and H. Takeda (1994), Evidence for excavation of deep crustal material of a Vesta-like body from $\mathrm{Ca}$ compositional gradients in pyroxene, Earth Planet. Sci. Lett., 122, 343-349, doi:10.1016/0012$821 \mathrm{X}(94) 90007-8$

Pun, A., and J. J. Papike (1996), Unequilibrated eucrites and the equilibrated Juvinas eucrite: Pyroxene REE systematics and major, minor, and trace element zoning, Am. Mineral., 81, 1438-1451.

Reid, A. M., and B. M. Barnard (1979), Unequilibrated and equilibrated eucrites, Lunar Planet. Sci., X, 1019-1021.

Righter, K., and M. J. Drake (1997), A magma ocean on Vesta: Core formation and petrogenesis of eucrites and diogenites, Meteorit. Planet. Sci., 32, 929-944, doi:10.1111/j.1945-5100.1997.tb01582.x.
Russell, C. T., et al. (2007), Dawn mission to Vesta and Ceres, Earth Moon Planets, 101, 65-91, doi:10.1007/s11038-007-9151-9.

Ruzicka, A., G. A. Snyder, and L. A. Taylor (1997), Vesta as the howardite, eucrite and diogenite parent body: Implications for the size of a core and for large-scale differentiation, Meteorit. Planet. Sci., 32, 825-840, doi:10.1111/j.1945-5100.1997.tb01573.x.

Saiki, K., H. Takeda, and T. Ishii (2001), Mineralogy of Yamato-791192, HED breccia and relationship between cumulate eucrites and ordinary eucrites, Antarct. Meteorite Res., 14, 28-46.

Shearer, C. K., P. Burger, and J. J. Papike (2010), Petrogenetic relationships between diogenites and olivine diogenites: Implication for magmatism on the HED parent body, Geochim. Cosmochim. Acta, 74 , 4865-4880, doi:10.1016/j.gca.2010.05.015.

Shestopalov, D. I., L. A. McFadden, L. F. Golubeva, and L. O. Orujova (2010), About mineral composition of geologic units in the northern hemisphere of Vesta, Icarus, 209, 575-585, doi:10.1016/j.icarus.2010. 04.012 .

Stolper, E. (1977), Experimental petrology of eucritic meteorites, Geochim Cosmochim. Acta, 41, 587-611, doi:10.1016/0016-7037(77)90300-3.

Takeda, H. (1979), A layered crust model of a howardite parent body, Icarus, 40, 455-470, doi:10.1016/0019-1035(79)90039-3.

Takeda, H. (1997), Mineralogical records of early planetary processes on the howardite, eucrite, diogenite parent body with reference to Vesta, Meteorit. Planet. Sci., 32, 841-853, doi:10.1111/j.1945-5100.1997. tb01574.x.

Takeda, H., and A. L. Graham (1991), Degree of equilibration of eucritic pyroxenes and thermal metamorphism of the earliest planetary crust, Meteoritics, 26, 129-134.

Takeda, H., and H. Mori (1985), The diogenite-eucrite like and the crystallization history of crust of their parent body, Proc. Lunar Planet. Sci. Conf., 15th, part 2, J. Geophys. Res., 90, C636-C648.

Takeda, H., H. Mori, and K. Yanai (1981), Mineralogy of the Yamato diogenites as possible pieces of a single stone, Mem. Natl. Inst. Polar Res., 20, 81-99.

Warren, P. H. (1997), Magnesium oxide-iron oxide mass balance constraints and a more detailed model for the relationship between eucrites and diogenites, Meteorit. Planet. Sci., 32, 945-963, doi:10.1111/ j.1945-5100.1997.tb01583.x.

Yamaguchi, A., G. J. Taylor, and K. Keil (1996), Global crustal metamorphism of the eucrite parent body, Icarus, 124, 97-112, doi:10.1006/ icar.1996.0192.

Yamaguchi, A., G. J. Taylor, and K. Keil (1997), Metamorphic history of the eucritic crust of 4 Vesta, J. Geophys. Res., 102, 13,381-13,386, doi:10.1029/97JE00519.

Yamaguchi, A., et al. (2001), Post-crystallization reheating and partial melting of eucrite EET90020 by impact into the hot crust of asteroid 4 Vesta $\sim 4.50 \mathrm{Ga}$ ago, Geochim. Cosmochim. Acta, 65, 3577-3599, doi:10.1016/S0016-7037(01)00681-0.

Yamaguchi, A., J. A. Barrat, R. C. Greenwood, N. Shirai, C. Okamoto, T. Setoyanagi, M. Ebihara, I. A. Franchi, and M. Bohn (2009), Crustal partial melting on Vesta: Evidence from highly metamorphosed eucrites, Geochim. Cosmochim. Acta, 73, 7162-7182, doi:10.1016/j.gca.2009.07. 037.

J.-A. Barrat and M. Bohn, Domaines Océaniques, UMR 6538, Université de Brest, CNRS, IUEM, Place Nicolas Copernic, F-29280 Plouzané CEDEX, France.

M. Ito, Kochi Institute for Core Sample Research, JAMSTEC, B200 Monobe, Nankoku, Kochi 783-8502, Japan.

A. Yamaguchi, National Institute of Polar Research, Tachikawa, Tokyo 190-8518, Japan. (yamaguch@nipr.ac.jp) 